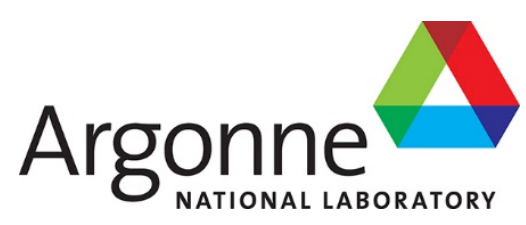

\title{
PROTEUS-NODAL User Manual
}

Revision 0

Nuclear Science and Engineering Division 


\begin{abstract}
About Argonne National Laboratory
Argonne is a U.S. Department of Energy laboratory managed by UChicago Argonne, LLC under contract DE-AC02-06CH11357. The Laboratory's main facility is outside Chicago, at 9700 South Cass Avenue, Argonne, Illinois 60439. For information about Argonne and its pioneering science and technology programs, see www.anl.gov.
\end{abstract}

\title{
DOCUMENT AVAILABILITY
}

Online Access: U.S. Department of Energy (DOE) reports produced after 1991 and a growing number of pre-1991 documents are available free via DOE's SciTech Connect (http://www.osti.gov/scitech/)

\author{
Reports not in digital format may be purchased by the public from the \\ National Technical Information Service (NTIS): \\ U.S. Department of Commerce \\ National Technical Information Service \\ 5301 Shawnee Rd \\ Alexandra, VA 22312 \\ www.ntis.gov \\ Phone: (800) 553-NTIS (6847) or (703) 605-6000 \\ Fax: (703) 605-6900 \\ Email: orders@ntis.gov \\ Reports not in digital format are available to DOE and DOE contractors from the \\ Office of Scientific and Technical Information (OSTI): \\ U.S. Department of Energy \\ Office of Scientific and Technical Information \\ P.O. Box 62 \\ Oak Ridge, TN 37831-0062 \\ www.osti.gov \\ Phone: (865) 576-8401 \\ Fax: (865) 576-5728
}

\begin{abstract}
Disclaimer
This report was prepared as an account of work sponsored by an agency of the United States Government. Neither the United States Government nor any agency thereof, nor UChicago Argonne, LLC, nor any of their employees or officers, makes any warranty, express or implied, or assumes any legal liability or responsibility for the accuracy, completeness, or usefulness of any information, apparatus, product, or process disclosed, or represents that its use would not infringe privately owned rights. Reference herein to any specific commercial product, process, or service by trade name, trademark, manufacturer, or otherwise, does not necessarily constitute or imply its endorsement, recommendation, or favoring by the United States Government or any agency thereof. The views and opinions of document authors expressed herein do not necessarily state or reflect those of the United States Government or any agency thereof, Argonne National Laboratory, or UChicago Argonne, LLC.
\end{abstract}




\section{PROTEUS-NODAL User Manual}

\section{Revision 0}

prepared by

Yeon Sang Jung, Changho Lee and Micheal A. Smith

Nuclear and Science Engineering Division, Argonne National Laboratory

September 30, 2018 



\section{ABSTRACT}

The PROTEUS-NODAL code is being developed as a three-dimensional (3D) neutron transport code based on homogenized geometry models of nuclear reactors. The code at present includes two solution options: diffusion theory and a nodal simplified $\mathrm{P}_{3}\left(\mathrm{SP}_{3}\right)$. The diffusion solution option is based upon the DIF3D-VARIANT $\mathrm{P}_{\mathrm{N}}$ transport methodology where the transport options have not been implemented due to the desire to create a $\mathrm{S}_{\mathrm{N}}$ based solution methodology. The diffusion solver works for Cartesian, hexagonal, and triangular-z geometries, while the $\mathrm{SP}_{3}$ solution option is currently available for hexagonal-z geometry only. Both diffusion and $\mathrm{SP}_{3}$ capabilities provide comparable solutions to DIF3D-VARIANT when using similar approximations. This document provides brief descriptions of inputs and outputs of the code. 


\section{TABLE OF CONTENTS}

Abstract i

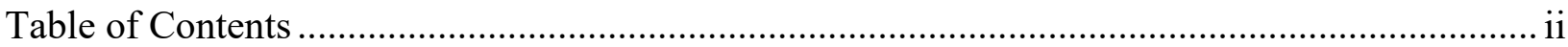

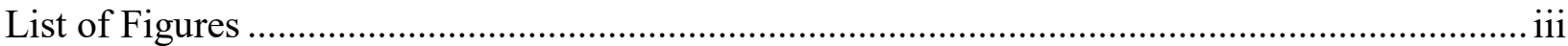

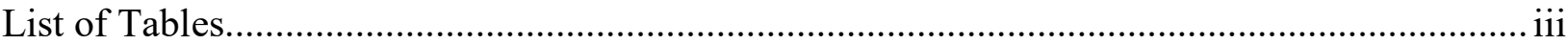

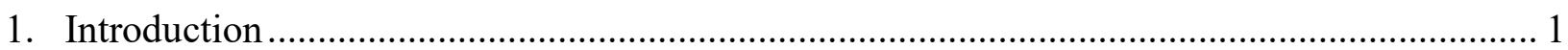

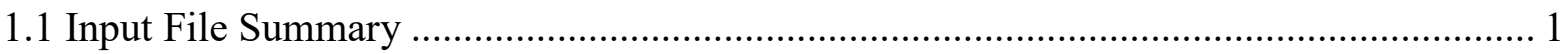

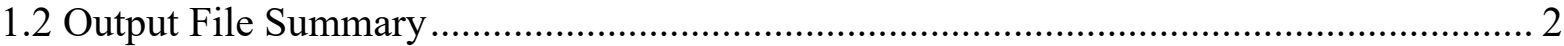

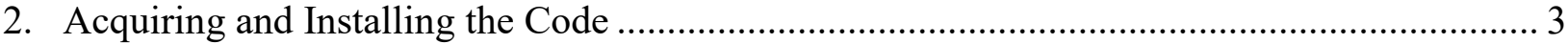

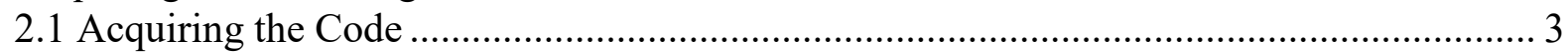

2.2 External Library Dependencies......................................................................... 3

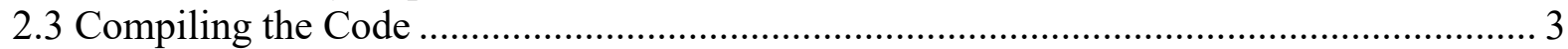

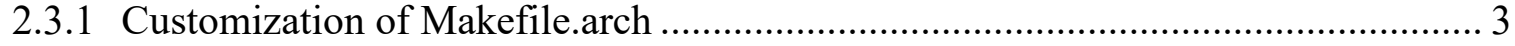

2.3.2 Customization of PROTEUS_Preprocess.h .................................................. 4

2.3.3 Building the Targets ................................................................................ 4

2.3.4 Recommended Compilers and Architectures ............................................... 4

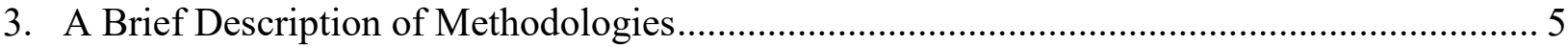

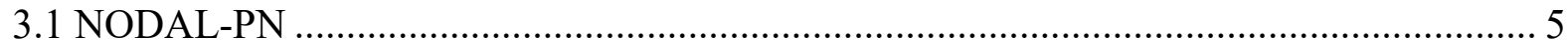

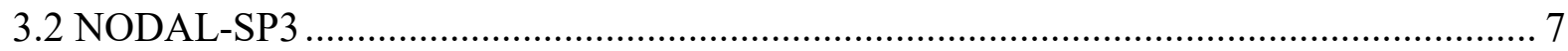

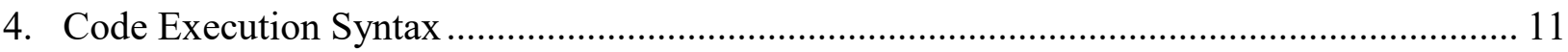

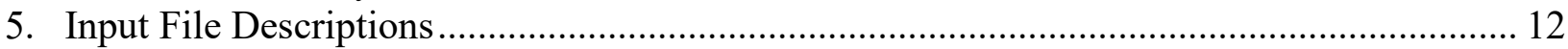

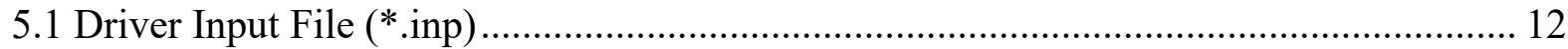

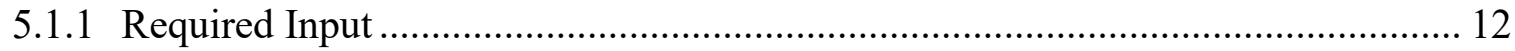

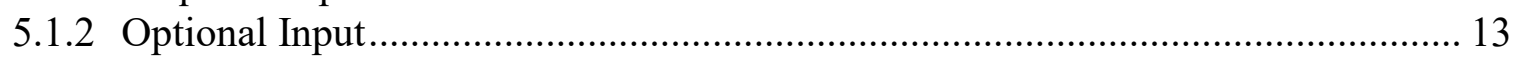

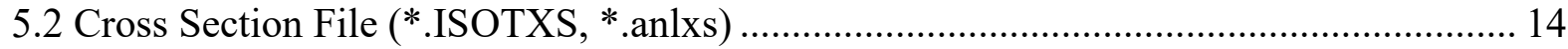

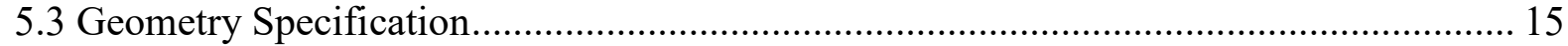

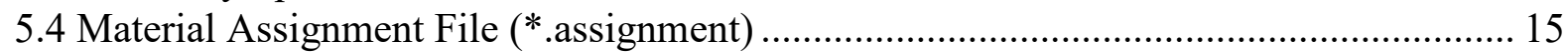

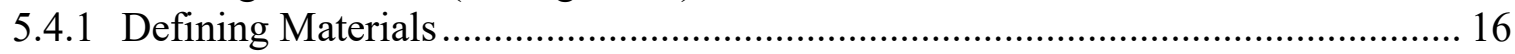

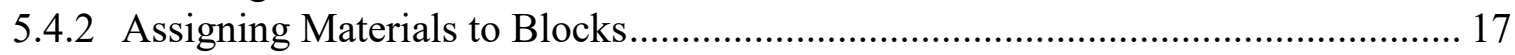

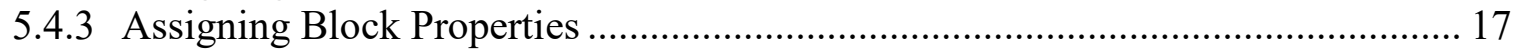

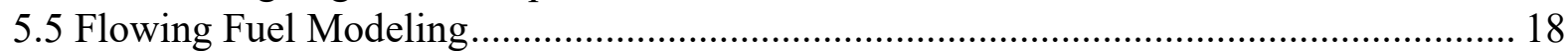

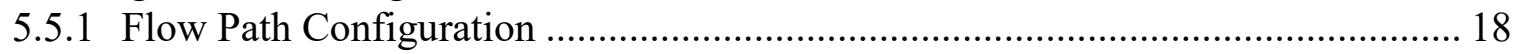

5.5.2 Fuel Flow Control......................................................................................... 19

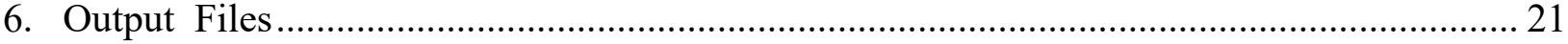

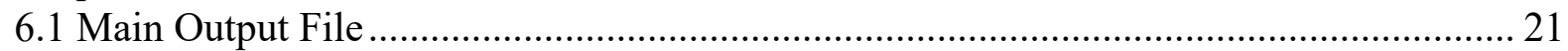

6.2 Summary Output File ........................................................................................... 22

6.3 VTK File .................................................................................................. 22

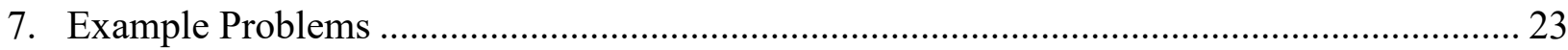

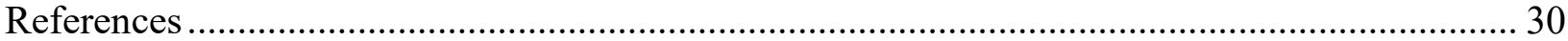




\section{LIST OF FIGURES}

Figure 2. Discretization of Hexagonal Node in the TPEN Method .......................................... 9

Figure 3. Unknowns of Local Problem for Hexagon Node in the TPEN Method.................... 10

Figure 4. Calculation Flow of PROTEUS-NODAL-SP3 Solver ............................................ 10

Figure 5. Material Definition in the Assignment File (Atom Fractions) ................................. 16

Figure 6. Material Definition in the Assignment File (Weight Fractions)............................... 16

Figure 7. Recursive Material Definition in the Assignment File ............................................. 17

Figure 8. Assigning a Material to a Block in the Assignment File ......................................... 17

Figure 9. Assigning Total Atom Density to a Block in the Assignment File .......................... 17

Figure 10. Assigning Total Mass Density to a Block in the Assignment File ........................ 17

Figure 11. Example PROTEUS-NODAL Assignment File..................................................... 18

Figure 12. Illustration of Flow Channel Configurations......................................................... 19

Figure 13. Configuring Flow Paths in Assignment File ………......................................... 19

Figure 14. Assigning Velocities to Blocks in Assignment File ............................................. 20

Figure 15. Assigning Delayed Times in Driver Input.......................................................... 20

Figure 16. Schematic Illustration of Input and Output Files.................................................. 21

Figure 17. Driver Input File for Example Case................................................................... 23

Figure 18. Mesh File for Example Case .......................................................................... 25

Figure 19. Region Map from the Mesh File at the Core Center ........................................... 26

Figure 20. Material Assignment File for Example Case........................................................ 27

Figure 21. Main Output for the Test Case............................................................................... 28

Figure 22. Power Density (left), Fast Neutron Flux (middle), and Precursor Family 1 (right) for the Test Case Plotted in VisIt ............................................................................. 29

\section{LIST OF TABLES}

Table 1. List of PROTEUS-NODAL Makefile Targets (Executables)...................................... 4

Table 2. Required Keywords for Driver Input File ............................................................... 12

Table 3. Input Cards in Driver Input File ............................................................................ 13

Table 4. Input Cards in Material Assignment File ............................................................... 15 



\section{Introduction}

The PROTEUS-NODAL code is being developed as a three-dimensional (3D) neutron transport code based on homogenized geometry models of nuclear reactors. The code presently includes two solution options: diffusion and a nodal simplified $\mathrm{P}_{3}\left(\mathrm{SP}_{3}\right)$. The diffusion solution is based upon the DIF3D-VARIANT $\mathrm{P}_{\mathrm{N}}$ transport methodology [1,2] of which diffusion theory has only been implemented. The diffusion solver works for Cartesian, hexagonal, and triangular-z geometries while the $\mathrm{SP}_{3}$ solution option is currently available for hexagonal-z geometry only. Both diffusion and $\mathrm{SP}_{3}$ capabilities provide comparable solutions to DIF3D-VARIANT when using comparable approximations. This document provides users with a guide for using PROTEUS-NODAL including the basics of carrying out simulations using the code. Note that the current version of the code is not parallel or threaded although significant research has been carried out on the subject as part of the NEAMS project.

\section{$1.1 \quad$ Input File Summary}

Four input files are required to perform PROTEUS calculations (two other files are relevant only for certain simulations).

a. Driver input file (*.inp)

b. Multigroup cross section file (*.ISOTXS, *.anlxs)

c. Mesh file (*.grid)

d. Material assignment file (*.assignment)

e. (Kinetics only) kinetics input file (*.inp)

The driver input file is a keyword-based free format text file that contains the simulation parameters such as angular cubature, parallelization, convergence criteria, and iteration limits.

The multigroup cross section file is a formatted file containing the multigroup cross sections for all the isotopes or materials of interest. Multigroup cross sections can be provided in either ANLXS, ISOTXS, or NODALXS formatted files.

The geometry details are given in a GRID formatted file which provides geometrical dimensions, region names, and boundary conditions and is part of the mesh generation toolkit [3]. In this manner, the results from the NODAL software can be visualized with the VTK file format which is also part of the toolkit. To define compositions and assign them to the geometrical regions we utilize the material assignment format that is already part of the PROTEUS framework.

The kinetics methodology is built on top of the existing steady state structure and is only relevant when running kinetics simulations. The kinetics input defines the timesteps to be simulated and requires material assignment files for each timestep along with delay cross section data and, if appropriate, a fixed source. The changes in materials or fixed source strength are assumed to drive the kinetics solution. 


\subsection{Output File Summary}

Execution of the PROTEUS-NODAL software yields a text output file, a integral summary file NODAL_SUMMARY.out and visualization output of NODAL_SUMMARY.vtk. The text output file contains an echo of the inputs, eigenvalue iteration history, and timing summaries. The NODAL_SUMMARY.out file includes a region-to-composition map and block-integrated quantities such as power densities, neutron group fluxes, etc. The NODAL_SUMMARY.vtk can be used to plot composition, geometry, flux and power solutions using VisIt [4] or any visualization tools file which can read a VTK formatted data file. 


\section{Acquiring and Installing the Code}

This chapter briefly describes how to obtain and install PROTEUS-NODAL. It lists the external library dependencies and also recommended compilers. For more specific (and up-todate) compilation information including configuration options of the various packages, one should consult the installation documentation included with the distribution.

\subsection{Acquiring the Code}

The PROTEUS-NODAL source code is export-controlled and currently obtained through Argonne National Laboratory. Contact nera-software@anl.gov for distribution information. The distribution package includes source code, build instructions, benchmark examples and documentation.

\subsection{External Library Dependencies}

PROTEUS-NODAL achieves distributed memory parallelization using the Message Passing Interface (MPI) protocol and uses the MPI2 standard typically through the MPICH2 [5] library implementation. PROTEUS-NODAL also has essential dependencies on two external packages, the mesh partitioning package METIS [6] which comes from its dependency upon the mesh toolkit. Additionally, PROTEUS-NODAL optionally interfaces with data format library HDF5 [7] although it presently will not generate an hdf5 based output file. For help installing any of the packages for use with PROTEUS-NODAL, refer to the documentation included with the distribution, or contact nera-software@anl.gov.

PROTEUS-NODAL uses the METIS package to determine the mesh partitioning scheme for spatial domain decomposition. To download METIS, visit the webpage http:/glaros.dtc.umn.edu/ gkhome/fsroot/sw/metis/OLD. PROTEUS-NODAL is currently configured to use METIS 4.0 or METIS 5.0. To use METIS 4.0, no action is necessary. To use METIS 5.0, the pre-processing variable PROTEUS_Use_METIS_VERSION_5 must be defined in PROTEUS_Preprocess.h.

\subsection{Compiling the Code}

Detailed compilation instructions are provided with the distribution, including suggested configuration options for many of the external dependencies. Once the external library dependencies have been downloaded and built, PROTEUS-NODAL is compiled using the provided makefile in the /source directory of the distribution. The makefile includes a second file, Makefile.arch, also located in the same directory.

\subsubsection{Customization of Makefile.arch}

Makefile.arch is a text file in the /source directory which contains typical compiler options and flags. We recommend you modify Makefile.arch to add an architecture-specific compilation section for your machine. 
It is recommended to add a section to Makefile.arch for your machine similar to above where the machine name should be recovered earlier in the script using the "uname" or "dnsdomainname" UNIX functions. In the file, the locations of MPICH compiler, METIS, and HDF5 should be assigned. Note that the F90 compiler must be specified individually as it is used to compile one of the kinetics routines.

\subsubsection{Customization of PROTEUS_Preprocess.h}

The header file PROTEUS_Preprocess.h [8] controls various data assignments via preprocessor directives. Most of the contents of this file should remain unchanged for routine use. However, the top few definitions can be commented or uncommented to enable debug printing, and to enable compilation with optional dependencies.

\subsubsection{Building the Targets}

Once you have customized Makefile.arch and PROTEUS_Preprocess.h, invoke the "make all" command from Linux command prompt inside the /source directory. This command creates all of the targets (executables) in Table 1. Alternatively, type "make $<$ target $>$ " at the command line to create only a specific target.

Table 1. List of PROTEUS-NODAL Makefile Targets (Executables)

\begin{tabular}{|l|l|}
\hline Target & Application \\
\hline nodal.x & Steady state version of PROTEUS-NODAL-PN \\
\hline nodal_sp3.x & Steady state version of PROTEUS-NODAL-SP3 \\
\hline
\end{tabular}

\subsubsection{Recommended Compilers and Architectures}

PROTEUS-NODAL has been regularly compiled with the following Intel compiler version 13.1 or older on Intel hardware. Compilation with GNU compilers should be relatively straightforward using the flags "-ffree-line-length-0 -ffixed-line-length-0" on the FFLAGS line in Makefile.arch. However, the code is not routinely tested with the GNU compilers so minor changes may be required for successful compilation and execution. 


\section{A Brief Description of Methodologies}

\subsection{NODAL-PN}

The NODAL methodology is a rewrite of the DIF3D-VARIANT methodology. In this methodology, we take the multigroup transport equation

$$
\begin{aligned}
\hat{\Omega} \cdot \vec{\nabla} \psi_{g}(\vec{r}, \hat{\Omega})+\Sigma_{t, g}(\vec{r}) \psi_{g}(\vec{r}, \hat{\Omega}) & =W_{g}(\vec{r}, \hat{\Omega})+S_{g}(\vec{r}, \hat{\Omega}) \\
W_{g}(\vec{r}, \hat{\Omega}) & =\int \Sigma_{s, g \rightarrow g}\left(\vec{r}, \hat{\Omega} \cdot \hat{\Omega}^{\prime}\right) \psi_{g}\left(\vec{r}, \hat{\Omega}^{\prime}\right) d \hat{\Omega}^{\prime},
\end{aligned}
$$

where $g=1, \ldots, G$ and, using an $\mathrm{P}_{1}$ angular approximation theory, recast it into the commonly known diffusion equation written in a functional form

$$
\begin{aligned}
& \int d V\left[\vec{\nabla} \lambda(\vec{r}) D_{g}(\vec{r}) \vec{\nabla} \phi_{g}(\vec{r})+\lambda(\vec{r}) \Sigma_{t, g}(\vec{r}) \phi_{g}(\vec{r})\right] \\
& =\int d V\left[\lambda(\vec{r}) \Sigma_{s, g \rightarrow g}(\vec{r}) \phi_{g}(\vec{r})+\lambda(\vec{r}) S_{g}(\vec{r})\right]-\sum_{\gamma} \int d \Gamma_{\gamma} \sum_{K} \hat{n}_{\gamma, K} V_{K} K_{\gamma} \Lambda \lambda(\vec{r}) \chi_{g, \gamma}(\vec{r}),
\end{aligned}
$$

where the notation is mostly standard except for the boundary condition term appearing on the right hand side of this equation. In this case, these are necessary to define the interface current (odd parity flux) contributions to the flux solution within each spatial mesh. By spatially discretizing this system, we can collapse the system into the matrix relationship

$$
\sum_{K, L} D_{g} P_{K, L} \phi_{g}+\Sigma_{t, g} F \phi_{g}=\Sigma_{s, g \rightarrow g} F \phi_{g}+F S_{g}-\sum_{\gamma} M_{\gamma} \chi_{g, \gamma} .
$$

We can collect the matrices to write the compact form

$$
A_{g} \phi_{g}=F S_{g}-\sum_{\gamma} M_{\gamma} \chi_{g, \gamma}
$$

which we can solve for the scalar flux

$$
\phi_{g}=A_{g}^{-1} F S_{g}-\sum_{\gamma} A_{g}^{-1} M_{\gamma} \chi_{g, \gamma} .
$$

To put this into a response matrix form, we impose continuity on the even- and odd-parity fluxes between spatial meshes and write

$$
\varphi_{g, \gamma}=F_{\gamma}^{-1} M_{\gamma}^{T} \phi_{g}=F_{\gamma}^{-1} M_{\gamma}^{T} A_{g}^{-1} F S_{g}-F_{\gamma}^{-1} M_{\gamma}^{T} \sum_{\gamma^{\prime}} A_{g}^{-1} M_{\gamma^{\prime}} \chi_{g, \gamma^{\prime}} .
$$

Because we need to solve the global system of nodes simultaneously, we assume partial currents of the form

$$
j_{g}^{ \pm}=\frac{1}{4} \varphi_{g} \pm \frac{1}{2} \chi_{g},
$$

which leads to the response matrix relationships of 


$$
j_{g}^{+}=R_{g} j_{g}^{-}+B_{g} S_{g}
$$

In PROTEUS-NODAL, the above system is setup assuming homogeneous cross sections within each spatial mesh although those cross sections can have a polynomial functionalization within the node. With this approach, orthogonal spatial basis functions internal and on the surfaces of the node are ideal when it comes to defining the spatial matrices. In DIF3DVARIANT, the matrix-vector operations are manually unrolled for each surface and the red-black iteration is applied hierarchically in the axial and radial directions. In PROTEUS-NODAL, the red-black iteration is applied in $3 \mathrm{D}$ and we allow the compiler to determine the optimal matrixvector operation. While we can show that the DIF3D-VARIANT approach is ideal in some reactor problems, using the full 3D sweeping in the partitioned matrix acceleration, matrix of PROTEUS-NODAL is always more efficient because of the better memory access pattern for the acceleration system and elimination of numerous intermediate vectors.

The DIF3D-VARIANT code actually chose the two level red-black scheme because of the memory constraints in the 1980s. With modern computers, we can handle a full red-black sweep over the entire domain for a given energy group as the total number of surface currents $(3 \cdot \mathrm{x} \cdot \mathrm{y} \cdot \mathrm{z}<$ 25,000 for most cases) and surface moments ( 3 for DIF3D-Nodal and 6 for DIF3D-VARIANT in diffusion $<150,000)$ leads to a small vector memory space $(<1.1 \mathrm{MB})$ which is within the typical cache size of most modern processors. More of an issue is the response matrix storage, which for 10,000 unique nodes leads to $12 \mathrm{MB}$ of memory. Given both of these are still under the $32 \mathrm{MB}$ level 3 cache, and unlikely to be less than the typical $2 \mathrm{MB}$ of level 2 cache even with the two level iterative scheme, we can improve the convergence by removing the extra iteration needed in the two level scheme. It is important to note that in most fast reactor problems this alone should eliminate $25 \%$ to $50 \%$ of the computational effort.

It is important to note that this approach was tried before in DIF3D-VARIANT with a negative outcome. In the two level scheme of DIF3D-VARIANT, the response matrix storage was not split to explicitly handle the separated axial and radial components (i.e. the ideal approach). Instead, the memory access pattern had to be setup to access the response matrix components using offsets when computing the axial current based source for each radial plane, solving each radial system, and updating the outgoing axial currents. Regardless, upon inspection, the two-level approach was found to constitute fewer response matrix related flops per iteration. Thus the conclusion was that the performance of the full red-black sweep was not as good as the two level approach but this did not consider the restrictions placed on the cache sizes which were much smaller at the time of the tests (2-4 MB instead of todays $32 \mathrm{MB}$ ). While we implemented the full 3D sweep, we did not have time to contrast it against DIF3D-VARIANT. If in the future we find that twolevel scheme is vastly superior to the $3 \mathrm{D}$ one, then we can switch to using the two-level scheme again.

Continuing, in DIF3D-VARIANT, there was a heavy focus placed on minimizing the vector storage of surface currents which arose due to the DIF3D-Nodal origination (where rotation of 
current moments was not an issue). In PROTEUS-NODAL, the same convention was followed but because of the desire to use a Krylov solver (GMRES or FGMRES), an additional layer of expansion/contraction was necessary as the surface currents are multiply defined in some geometry setups (e.g. periodic and symmetry domains). In the previous work, the expansion/contraction approach resulted in a complex if branch operation in the main iterative (repeating) segment of the NODAL solver. In the updated PROTEUS-NODAL, both the DIF3DVARIANT and the previous approaches were discarded as storing the full vector resulted in the minimal if branching during the iterative solver phase. While this does increase the memory usage slightly, it maximizes the potential success for threading as it allows the current vector components of each node to be independent memory targets.

Because of the rather minor success of energy parallelism and usage of GMRES/FGMRES, all aspects of the Krylov solver were removed as was the parallelism in energy concept. At the moment, the new version is thus completely serial although we are targeting OpenMP threading to allow it to better utilize the cores on a given node.

\subsection{NODAL-SP3}

The $\mathrm{SP}_{3}$ equation, which is an approximated version of the $\mathrm{P}_{3}$ equation, is known to be able to capture the major transport effects in both fast and thermal reactors. [9] With affordable additional computation cost, $\mathrm{SP}_{3}$ can render significantly improved accuracy over the conventional diffusion equation. Moreover, it can be readily expanded for the full spatial kinetics by adopting the well-established methods for the diffusion equation. In order to support steadystate and transient analyses for routine design practices, the $\mathrm{SP}_{3}$ nodal option was added to the PROTEUS-NODAL solver. Currently the $\mathrm{SP}_{3}$ nodal option can provide the steady-state and transient solutions of the $\mathrm{SP}_{3}$ equation for $3 \mathrm{D}$ hexagonal geometries.

In the $\mathrm{SP}_{3}$ nodal capability, the $\mathrm{SP}_{3}$ equation is efficiently solved by combining the $2 \mathrm{D}$ triangle based polynomial expansion nodal (TPEN) method and 1D nodal expansion method (NEM) for radial and axial directions, respectively. [10,11] The convergences of eigenvalue and fission source are accelerated by employing the diffusion CMFD method.

The 3D steady-state $\mathrm{SP}_{3}$ equation with the transport approximation is given as:

$$
\left[\begin{array}{cc}
-D_{i} & -2 D_{i} \\
0 & -D_{i}^{2}
\end{array}\right]\left[\begin{array}{l}
\nabla^{2} \phi_{i}^{0}(\vec{r}) \\
\nabla^{2} \phi_{i}^{2}(\vec{r})
\end{array}\right]+\left[\begin{array}{cc}
\Sigma_{r g, i} & 0 \\
-\frac{2}{3} \Sigma_{r g, i} & \frac{5}{3} \Sigma_{t, i}
\end{array}\right]\left[\begin{array}{l}
\phi_{i}^{0}(\vec{r}) \\
\phi_{i}^{2}(\vec{r})
\end{array}\right]=\left[\begin{array}{l}
q_{i}^{0}(\vec{r}) \\
q_{i}^{2}(\vec{r})
\end{array}\right],
$$

where $\phi_{i}^{k}$ denotes the $k$-th flux moment on the $i$-th mesh, and the group index is omitted for brevity. The diffusion constant for the $2^{\text {nd }}$ flux moment, $D_{i}^{2}$, is defined as:

$$
D_{i}^{2}=\frac{3}{7 \Sigma_{t, i}} .
$$

By introducing a new solution variable $\hat{\phi}_{i}=\phi_{i}^{1}+2 \phi_{i}^{2}$, Eq. (2-19) can be further simplified as: 


$$
\left[\begin{array}{cc}
-D_{i} & 0 \\
0 & -D_{i}^{2}
\end{array}\right]\left[\begin{array}{l}
\nabla^{2} \hat{\phi}_{i}(\vec{r}) \\
\nabla^{2} \phi_{i}^{2}(\vec{r})
\end{array}\right]+\left[\begin{array}{cc}
\Sigma_{r g, i} & -2 \Sigma_{r g, i} \\
-\frac{2}{3} \Sigma_{r g, i} & \frac{4}{3} \Sigma_{r g, i}+\frac{5}{3} \Sigma_{t, i}
\end{array}\right]\left[\begin{array}{l}
\hat{\phi}_{i}(\vec{r}) \\
\phi_{i}^{2}(\vec{r})
\end{array}\right]=\left[\begin{array}{c}
q_{i}^{0}(\vec{r}) \\
q_{i}^{2}(\vec{r})
\end{array}\right] .
$$

The currents for the $0^{\text {th }}$ and $2^{\text {nd }}$ flux moments can be determined using the following relations:

$$
\begin{gathered}
J_{i}^{0}(\vec{r})=-D_{i} \nabla^{2} \hat{\phi}_{i}(\vec{r})=-D_{i}\left(\nabla^{2} \phi_{i}^{0}(\vec{r})+\nabla^{2} \phi_{i}^{2}(\vec{r})\right), \\
J_{i}^{2}(\vec{r})=-D_{i}^{2} \nabla^{2} \phi_{i}^{2}(\vec{r}) .
\end{gathered}
$$

For a set of homogenized hexagonal assemblies configured in a triangle lattice, the NODAL$\mathrm{SP}_{3}$ solver solves the two $\mathrm{SP}_{3}$ equations for the radial and axial directions, which are coupled through the transverse leakages. To resolve the implicit couplings through the transverse leakage, the alternating nodal calculations for the radial and axial directions are performed. In this manner, the transverse leakage used for a one direction calculation is obtained from the solution of the other direction. Once the solution for one direction is obtained in the alternative solution process, the transverse leakage is updated and fed up to the subsequent calculation for the other direction. In the current implementation of the $\mathrm{SP}_{3}$ nodal solver, the solution of the radial equation is determined by employing the 2D TPEN method and the 1D NEM is applied to the axial equation.

In the 2D $\mathrm{SP}_{3}$ TPEN method, the solutions for individual hexagonal meshes are determined using the response matrix technique. The response matrix of each hexagon can be derived by solving the local problem for the hexagon using the local boundary conditions for surface currents and vertex fluxes. In this local problem, a hexagon node is divided into 6 triangular sub-nodes as shown in Figure 1 and an intra-nodal flux distribution is represented with a cubic polynomial. The intra-nodal flux distributions of six sub-meshes are simultaneously determined using the surface average incoming currents and vertex fluxes of hexagonal mesh along with additional constraints. Note that a single polynomial is used to represent the intra-nodal solution in the DIF3DVARIANT method. In the TPEN method, the additional interfacial conditions on the internal surfaces are involved, which can adversely affect the solution accuracy. However, the TPEN approach is advantageous in that the flux variation within the homogenized node can be represented in a relatively concise form.

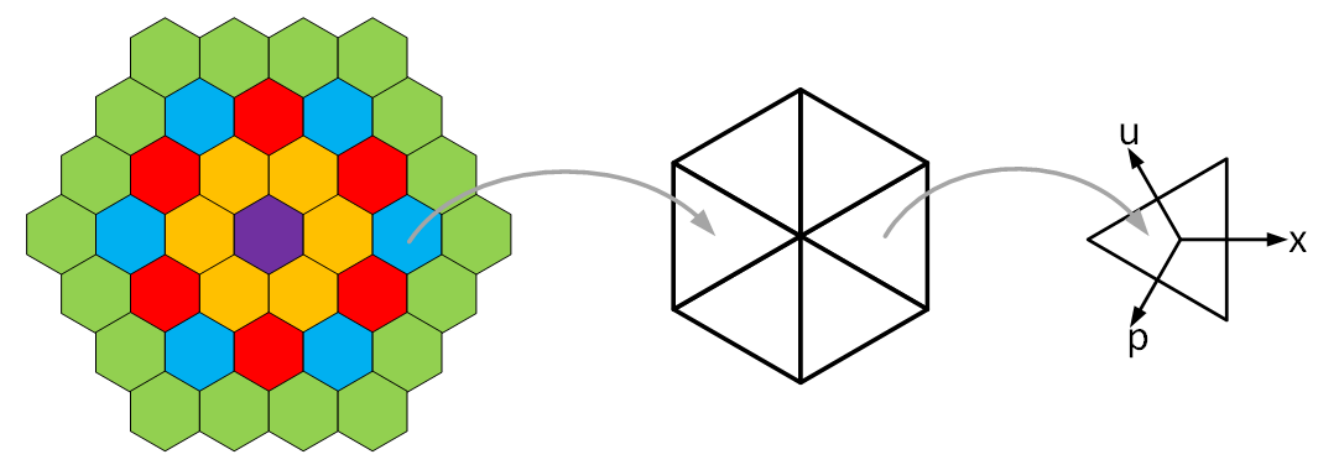




\section{Figure 1. Discretization of Hexagonal Node in the TPEN Method}

In each triangular node, the local coordinates $x, u$ and $p$, which are perpendicular to triangle surfaces, are introduced as shown in Figure 1 . Then, the intra-nodal fluxes for the $0^{\text {th }}$ and $2^{\text {nd }}$ flux moments are represented with the cubic polynomials having nine expansion coefficients to be determined:

$$
\phi^{m}=c_{o}^{m}+a_{x}^{m} x+a_{y}^{m} y+b_{x}^{m} x^{2}+b_{u}^{m} u^{2}+b_{p}^{m} p^{2}+c_{x}^{m} x^{3}+c_{u}^{m} u^{3}+c_{p}^{m} p^{3} .
$$

Yielding the response matrix, the 9 expansion coefficients in Eq. (3-14) can be alternatively expressed in terms of the following 9 quantities defined on each triangular node: the average, $\mathrm{x}$ moment and y-moment fluxes, surface average fluxes for three surfaces and vertex fluxes on three vertices. Consequently, a single hexagon has 54 unknowns in total for each flux moment. By noting that the vertex fluxes of hexagon are given and the continuity conditions are imposed on the triangle vertices and the internal surfaces, as shown in Figure 2, the number of unknowns to be determined is reduced to the following 31 quantities: average, $\mathrm{x}$-moment and y-moment fluxes for the 6 triangular meshes, surface average fluxes for the 6 hexagon surfaces, surface average fluxes for the 6 internal surfaces and vertex fluxes on the hexagon center.

In order to determine the above quantities uniquely, the following 25 constraints are imposed along with the incoming partial currents for the six hexagon surfaces:

- Neutron balance equation for each triangular meshes (6 constraints)

- $\mathrm{x}$ - and $\mathrm{y}$-weighed residual equations for each triangle meshes (12 constraints)

- Surface current continuity for each internal surface (6 constraints)

- Source-free condition in the hexagon center (1 constraint)

The detailed derivation of response matrix and its solution technique can be found elsewhere $[10,11]$.

In the $1 \mathrm{D} \mathrm{SP}_{3} \mathrm{NEM}$ for the axial direction, the solution of each axial mesh is expanded using the $4^{\text {th }}$ order orthogonal polynomials and its coefficients are determined through the conventional one-node nodal technique. In the current implementation of 1D NEM module of NODAL-SP3 solver, the following conditions/constraints are used to determine the intra-nodal flux shape for axial meshes:

- Node average flux

- Partial incoming currents at the top and bottom surfaces

- $\mathrm{x}$ - and $\mathrm{y}$-weighed residual equations for the axial mesh

The axial nodal solver uses the node average flux and radial transverse leakage from the radial solution and it updates the axial currents on the top and bottom of hexagonal meshes. Hence, the axial nodal solver can be viewed as the embedded procedure on the radial solver to account for the axial streaming effect. The overall calculation procedure of NODAL-SP3 solver is illustrated in Figure 3. 


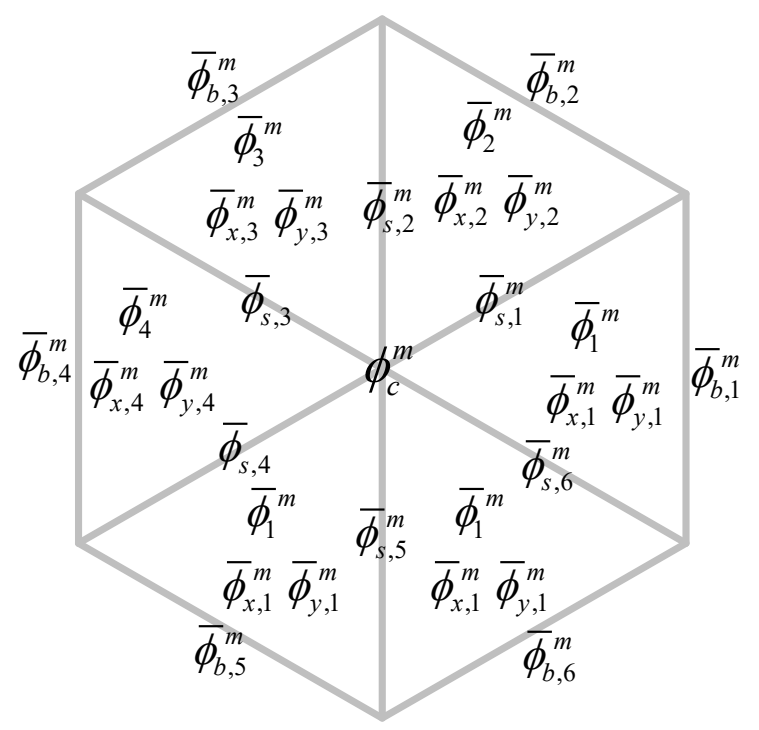

Figure 2. Unknowns of Local Problem for Hexagon Node in the TPEN Method

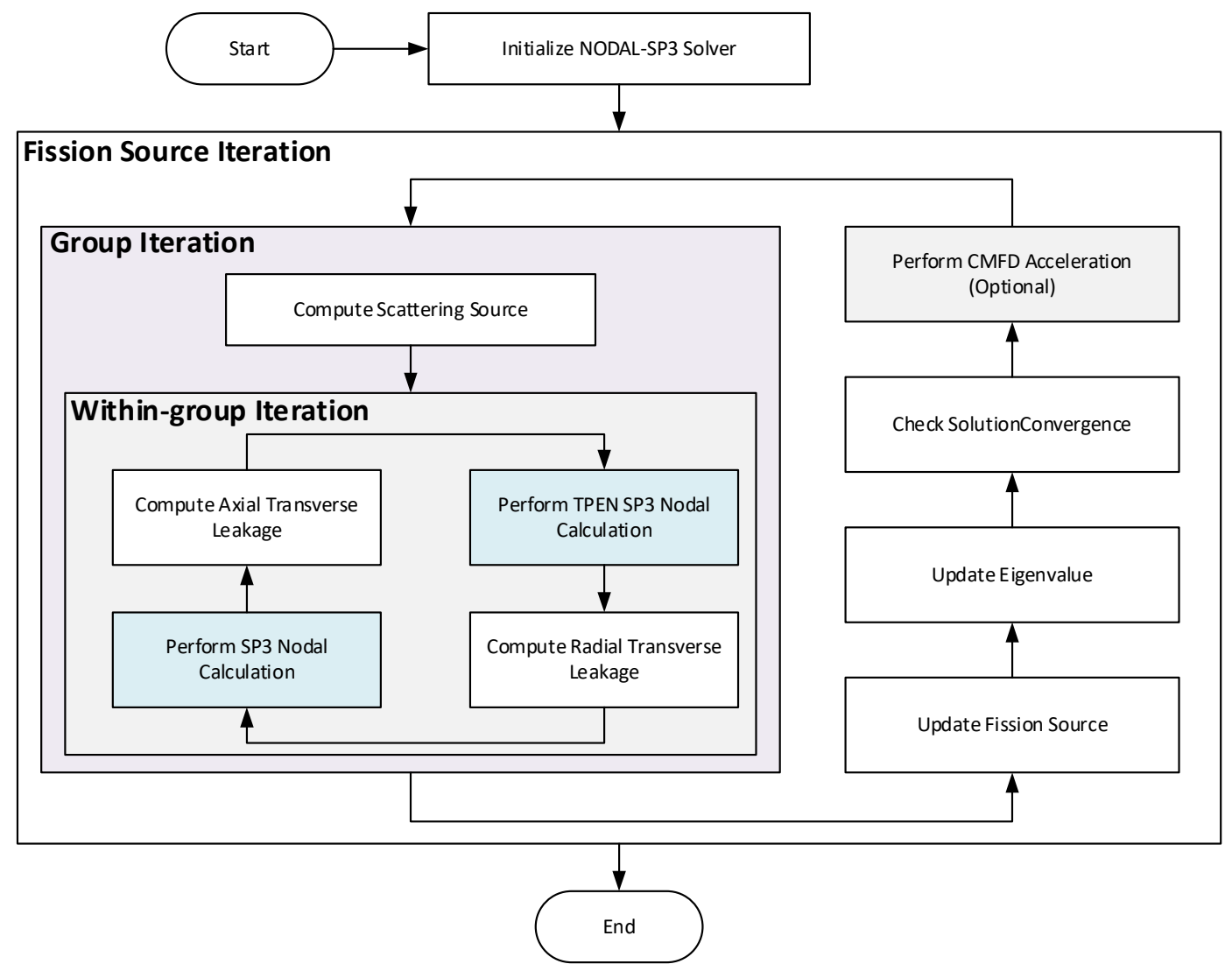

Figure 3. Calculation Flow of PROTEUS-NODAL-SP3 Solver 


\section{Code Execution Syntax}

PROTEUS-NODAL is executed via command line on Linux platforms. To perform a serial job with the steady state solver, type the following at the command prompt (assuming the executable is in the current directory or in the user's path):

$\$$ nodal.x -input mydriver.inp -output mydriver.out

\$ nodal_sp3.x -input mydriver.inp -output mydriver.out

The "-input" flag argument specifies that PROTEUS-NODAL should look for a specific driver input file in the location specified by the following argument. If the "-input" flag and argument is omitted, PROTEUS-NODAL looks for the driver input file in the current working directory with the default name "nodal.inp". The output can be redirected from standard output to a file using the -output flag. 


\section{Input File Descriptions}

This section describes the required input files for a PROTEUS-NODAL calculation:

- Driver input file

- Cross section file

- Mesh file

- Material assignment file

\subsection{Driver Input File (*.inp)}

Upon execution, PROTEUS looks for the driver input file, "nodal.inp", in the current working directory. This input file is a plain text (ASCII) file that drives the PROTEUS calculation by specifying solver tolerances, the angular discretization, parallelization options, and other input options. Additionally, the UNIX file paths to the other input files (cross sections, mesh, and material assignment file) are specified. Input options are specified in the file by special keywords which can appear in any order.

To use a different file name for the driver input such as "nodal_5g_mesh1.inp", you need to add the command line option "-input nodal_5g_mesh1.inp" at execution to alert PROTEUS of the driver input file name.

\subsubsection{Required Input}

Table 2 shows the essential driver level input required in every PROTEUS-NODAL calculation. The keywords and values are not case sensitive. Default values are listed when applicable.

Table 2. Required Keywords for Driver Input File

\begin{tabular}{|l|c|c|l|}
\hline \multicolumn{1}{|c|}{ Keyword } & Input Data & $\begin{array}{c}\text { Default } \\
\text { value }\end{array}$ & \multicolumn{1}{|c|}{ Description } \\
\hline \hline SOURCEFILE_MESH & $\begin{array}{c}\text { <Max } 128 \\
\text { Characters }\end{array}$ & - & $\begin{array}{l}\text { Specifies the UNIX file } \\
\text { path to a spatial } \\
\text { geometry mesh file }\end{array}$ \\
\hline SOURCEFILE_XS & <Max 128 & - & $\begin{array}{l}\text { Specifies the Unix file } \\
\text { path to a cross section } \\
\text { data file }\end{array}$ \\
\hline SOURCEFILE_MATERIAL & Characters & - & $\begin{array}{l}\text { Specifies the Unix file } \\
\text { path to a material } \\
\text { mapping file }\end{array}$ \\
\hline THERMAL_POWER & Characters & 100.0 & $\begin{array}{l}\text { Specifies the thermal } \\
\text { power (W unit) for } \\
\text { properly normalizing the } \\
\text { flux and power solutions }\end{array}$ \\
\hline
\end{tabular}




\begin{tabular}{|l|l|l|l|}
\hline Keyword & Input Data & $\begin{array}{c}\text { Default } \\
\text { value }\end{array}$ & \multicolumn{1}{|c|}{ Description } \\
\hline \hline & & & provided in output file \\
\hline
\end{tabular}

\subsubsection{Optional Input}

Other optional driver-level input options are listed in Table 3. They can be classified into the following groups: iterative solver options, cross section options, output file options and flowing fuel option.

Table 3. Input Cards in Driver Input File

\begin{tabular}{|c|c|c|c|}
\hline Keyword & Input Data & $\begin{array}{c}\text { Default } \\
\text { value }\end{array}$ & Description \\
\hline \multicolumn{4}{|c|}{ Iterative Solver Options } \\
\hline EIGENVALUE_GUESS & $<$ Real Value $>$ & 1.0 & $\begin{array}{l}\text { Guess for the initial } \\
\text { eigenvalue. }\end{array}$ \\
\hline MAX_FISSION_ITER & $<$ Integer $>0>$ & 100 & $\begin{array}{l}\text { Maximum number of } \\
\text { outer (fission source) } \\
\text { iterations. }\end{array}$ \\
\hline TOLERANCE_EIGENVALUE & $<$ Real Value $>$ & $1.0 \mathrm{E}-6$ & $\begin{array}{l}\text { Targeted relative error } \\
\text { on the eigenvalue. }\end{array}$ \\
\hline TOLERANCE_FISSION & $<$ Real Value $>$ & $5.0 \mathrm{E}-6$ & $\begin{array}{l}\text { Targeted relative error } \\
\text { on the fission source. }\end{array}$ \\
\hline TOLERANCE_FLUX & $<$ Real Value $>$ & $1.0 \mathrm{E}-7$ & $\begin{array}{l}\text { Targeted relative error } \\
\text { on the flux solution. }\end{array}$ \\
\hline \multicolumn{4}{|c|}{ Cross Section Options } \\
\hline USE_TRANSPORT_XS & $\begin{array}{l}\text { YES } \\
\text { NO }\end{array}$ & NO & $\begin{array}{l}\text { Indicates that the } \\
\text { transport corrected cross } \\
\text { section is to be used as } \\
\text { the "total" cross section. } \\
\text { All anisotropic scattering } \\
\text { data is ignored. }\end{array}$ \\
\hline USE_DIF3D_CHI & $\begin{array}{l}\text { YES } \\
\text { NO }\end{array}$ & NO & $\begin{array}{l}\text { Specify whether the } \\
\text { composition-wise chi is } \\
\text { to be used in the fission } \\
\text { source update. Note } \\
\text { DIF3D uses the } \\
\text { composition-wise chi } \\
\text { instead of isotopic-wise } \\
\text { one. }\end{array}$ \\
\hline
\end{tabular}




\begin{tabular}{|c|c|c|c|}
\hline Keyword & Input Data & $\begin{array}{c}\text { Default } \\
\text { value }\end{array}$ & Description \\
\hline SOURCEFILE_DELAY & $\begin{array}{l}<\text { Max } 128 \\
\text { Characters> }\end{array}$ & - & $\begin{array}{l}\text { Specifies the Unix file } \\
\text { path to a DLAYXS file. } \\
\text { NOTE: } \\
\text { USE_FLOWINGFUEL } \\
\text { should be turned on to } \\
\text { make this input } \\
\text { meaningful. }\end{array}$ \\
\hline \multicolumn{4}{|c|}{ Output File Options } \\
\hline EXPORT_SOLUTION_VTK & $\begin{array}{l}\text { YES } \\
\text { NO }\end{array}$ & NO & $\begin{array}{l}\text { Export the output to a } \\
\text { VTK file for visualization. }\end{array}$ \\
\hline \multicolumn{4}{|c|}{ Flowing Fuel Options } \\
\hline USE_FLOWINGFUEL & $\begin{array}{l}\text { YES } \\
\text { NO }\end{array}$ & NO & $\begin{array}{l}\text { Activate the flowing fuel } \\
\text { option }\end{array}$ \\
\hline CHANNEL_INFO & $\begin{array}{l}1^{\text {st }}<\text { Integer Value }> \\
2^{\text {nd }}<\text { Character Value }> \\
3^{\text {rd }}<\text { Real Value }>\end{array}$ & - & $\begin{array}{l}\text { Define channel ID, name, } \\
\text { and time spent outside } \\
\text { the core (sec) } \\
1^{\text {st }} \text { : channel ID } \\
2^{\text {nd }}: \text { channel name } \\
3^{\text {rd }}: \text { time outside core (s) } \\
\text { NOTE: } \\
\text { USE_FLOWINGFUEL } \\
\text { should be turned on to } \\
\text { make this input work. }\end{array}$ \\
\hline
\end{tabular}

\subsection{Cross Section File (*.ISOTXS, *.anlxs)}

The cross section file consists of the multigroup cross sections for all isotopes and/or compositions in the problem. Multigroup cross sections must be provided in one of the following formats:

a. ISOTXS (binary file)

b. ANLXS (ASCII file)

c. NODALXS (ASCII file)

The ISOTXS format is the preferred file format for cross section data used by PROTEUSNODAL. The $\mathrm{MC}^{2}-3$ code [13] can be used to process multigroup cross sections in this format. Additionally, the DRAGON code [14] has a capability to generate an ISOTXS file. The Serpent [15] and OpenMC [16] Monte Carlo codes can be used to generate cross sections, for which their 
cross section outputs should be converted to an ISOTXS format file using the GenISOTXS code [17]. Note that Serpent generates macroscopic cross sections only.

The ANLXS file format is a simple ASCII interpretation of the data provided in ISOTXS while the NODALXS file format was built to allow polynomial and tabulated data sets to be provided. Any ANLXS file format that is provided is converted into the appropriate ISOTXS file at runtime and both are converted to a NODALXS file for use in the NODAL solver.

The cross section file does not need to be located in the working directory. The UNIX file path to the cross section file must always be specified in the driver input file using the SOURCEFILE_XS keyword.

\subsection{Geometry Specification}

The geometry file is a GRID formatted file containing information on geometric dimensions, region names, and boundary conditions. The GRID file is part of the mesh generation toolkit [3] and thus the NODAL solutions can be visualized with the VTK option of the toolkit.

\subsection{Material Assignment File (*.assignment)}

The material assignment (*.assignment) file performs three main functions: (1) define materials or mixtures of the isotopes in the cross section file, (2) assign these materials to regions in the mesh, and (3) assign properties (e.g. density and temperature) to regions in the mesh. The material assignment file uses simple keyword-based inputs in a free format, as shown in Table 4. It is normally created by the user, although a Python script is available to speed up the process. Comments start with either "!" or "\#”.

Table 4. Input Cards in Material Assignment File

\begin{tabular}{|l|c|c|l|}
\hline Keyword & \multicolumn{1}{|c|}{ Input Data } & $\begin{array}{c}\text { Default } \\
\text { value }\end{array}$ & \multicolumn{1}{|c|}{ Description } \\
\hline \hline REGION_PROPERTY & $\begin{array}{c}1^{\text {st }}<\text { Character Value }> \\
2^{\text {nd }}<\text { Character Value } \\
3^{\text {rd }}<\text { Real } / \text { Integer } \\
\text { Value }\end{array}$ & - & $\begin{array}{l}\text { Define region properties } \\
\text { such as atom/mass } \\
\text { density. }\end{array}$ \\
\hline REGION_ALIAS & $\begin{array}{l}1^{\text {st }}<\text { Character Value }> \\
2^{\text {nd }}<\text { Character Value }>\end{array}$ & - & $\begin{array}{l}\text { Assign user-defined } \\
\text { materials to regions. }\end{array}$ \\
\hline MATERIAL_DEF & $\begin{array}{l}1^{\text {st }}<\text { Character Value }> \\
2^{\text {nd }}<\text { Character Value }> \\
\text { rd }<\text { Real Value }>\end{array}$ & $\begin{array}{l}\text { Create user-defined } \\
\text { materials based on } \\
\text { isotopes in the cross } \\
\text { section file. Recursive } \\
\text { definitions are allowed to } \\
\text { create additional } \\
\text { mixtures. }\end{array}$ \\
\hline
\end{tabular}




\subsubsection{Defining Materials}

The isotope names provided in the cross section files are all available for use in defining materials. Figure 4 demonstrates the definition of a material called FUEL from 8 isotopes appearing in the cross section file: "U234A", "U235A", etc... The keyword MATERIAL_DEF is used repeatedly to add compositions to the material FUEL with the given atom fractions. The sum of all atom fractions is renormalized to 1 inside PROTEUS-NODAL. In this way, the true atom densities can be given (in \#/barn-cm) for easier recordkeeping or in the natural concentrations of the component molecule.

\begin{tabular}{|lll|}
\hline MATERIAL_DEF & FUEL U234A & $2.7572 \mathrm{E}-5$ \\
MATERIAL_DEF & FUEL U235A & $2.5533 \mathrm{E}-3$ \\
MATERIAL_DEF & FUEL U236A & $9.5684 \mathrm{E}-6$ \\
MATERIAL_DEF & FUEL U238A & $1.5316 \mathrm{E}-4$ \\
MATERIAL_DEF & FUEL B10A & $1.5539 \mathrm{E}-4$ \\
MATERIAL_DEF & FUEL B11A & $6.2547 \mathrm{E}-4$ \\
MATERIAL_DEF & FUEL C12A & $1.9521 \mathrm{E}-4$ \\
MATERIAL_DEF & FUEL ALA & $5.2751 \mathrm{E}-2$ \\
\hline
\end{tabular}

Figure 4. Material Definition in the Assignment File (Atom Fractions)

Figure 5 demonstrates the definition of a material called Water from 2 isotopes appearing in the cross section file, "H_ $\mathrm{H}_{1}$ " and "O__ 16". The negative fraction indicates that the value is given in terms of weight fraction rather than atom fraction.

$$
\begin{array}{lll}
\text { MATERIAL_DEF Water } \mathrm{H} \_1 & -0.1121 \\
\text { MATERIAL_DEF Water } 0 \_16 & -0.8879
\end{array}
$$

\section{Figure 5. Material Definition in the Assignment File (Weight Fractions)}

Figure 6 demonstrates the definition of a material called Water from 2 isotopes appearing in the cross section file, "H1" and "O16", as well as the definition of a material called Salt from isotopes "NA23" and "Chlor". The fractions are assumed to be atom fractions since they are positive. The last MATERIAL_DEF line defines a mixture called Saline which is $0.9 \%$ Salt and 99.1\% Water. This example demonstrates the recursive usage of the MATERIAL_DEF keyword. It is not permitted to mix weight fractions and atom fractions in the same definition of a material. 


\begin{tabular}{|lcc|}
\hline MATERIAL_DEF Water H1 & 2.0 \\
MATERIAL_DEF Water 016 & 1.0 \\
& & \\
MATERIAL_DEF Salt NA23 & 1.0 \\
MATERIAL_DEF Salt Chlor & 1.0 \\
& & \\
MATERIAL_DEF Saline 0.009 & Salt 0.991 Water \\
\hline
\end{tabular}

Figure 6. Recursive Material Definition in the Assignment File

\subsubsection{Assigning Materials to Blocks}

In the previous section, we defined a material called FUEL. We can assign this material (or any other composition appearing in the material assignment file or the cross section file) to a region in the mesh. The ASSEMBLY001 (block name was defined by the user during mesh creation) is supposed to be a fuel assembly. We can associate the material FUEL using the REGION_ALIAS keyword shown in Figure 7.

REGION_ALIAS ASSEMBLYOO1 FUEL

Figure 7. Assigning a Material to a Block in the Assignment File

\subsubsection{Assigning Block Properties}

We have not yet accounted for the actual material density of the block, or any other properties. The previous step simply linked cross section data to a specific region. If macroscopic cross section data was provided, no further action is necessary since the number density is incorporated into the data. More typically, the cross section data file contains microscopic cross section data and the density must be assigned. Figure 8 demonstrates the assignment of total atom density to 5.6129E-02 atoms/barn-cm using the keywords REGION_PROPERTY and ATOM_DENSITY.

REGION_PROPERTY ASSEMBLYO01 ATOM_DENSITY 5.6129E-02

Figure 8. Assigning Total Atom Density to a Block in the Assignment File

Alternatively, the total mass density in $\mathrm{g} / \mathrm{cm}^{3}$ can be assigned to a block as shown in Figure 9 . When using the Density $(\mathrm{g} / \mathrm{cc}$ ) property, PROTEUS uses the mass specified in the ISOTXS file for each basic component to convert to number density.

REGION_PROPERTY ASSEMBLYOO1_Density (g/cC) 8.595

Figure 9. Assigning Total Mass Density to a Block in the Assignment File 
The keyword REGION_PROPERTY is therefore used to assign various properties to the mesh such as ATOM_DENSITY, Density(g/cc), TEMPERATURE(K), and MATERIAL_MODEL to each mesh region. This approach is similar to MCNP where the same material can be used for multiple regions but at different concentrations. For the standard PROTEUS-NODAL user, the only properties of interest are Density $(\mathrm{g} / \mathrm{cc})$ and ATOM_DENSITY.

An example of a complete assignment file for a fictitious problem is shown in Figure 10. This assignment file assigns materials to two blocks.

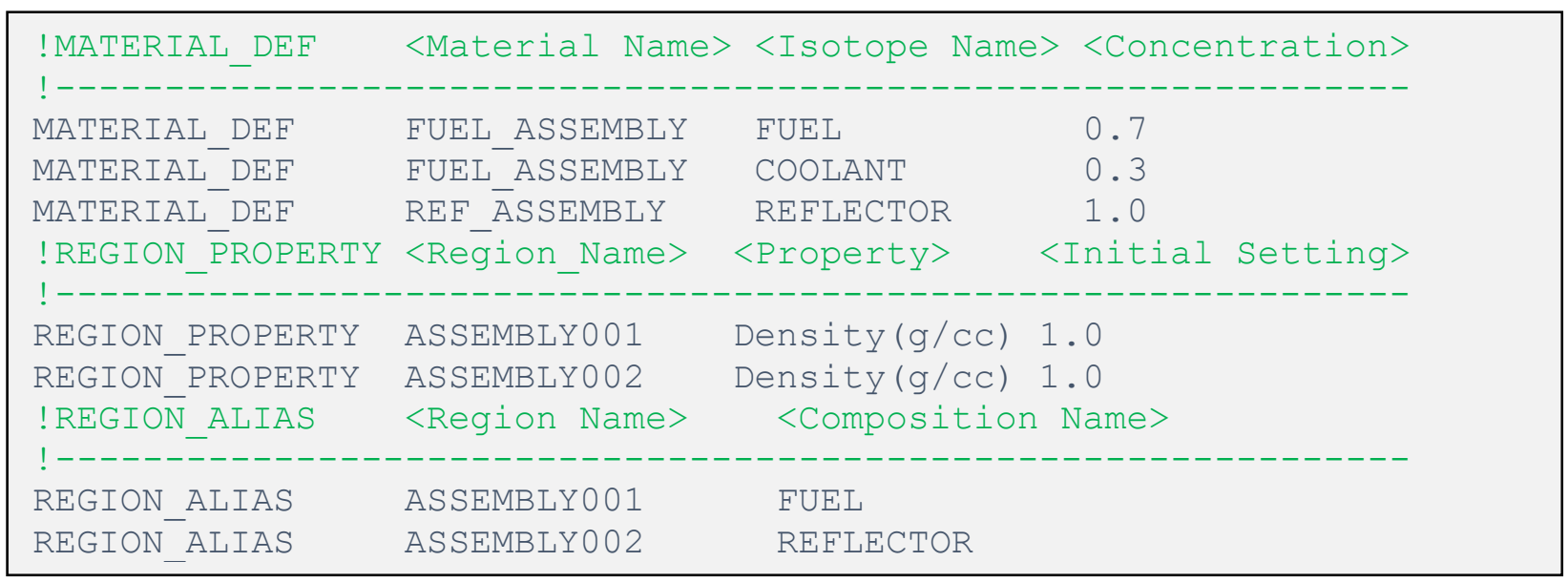

Figure 10. Example PROTEUS-NODAL Assignment File

\subsection{Flowing Fuel Modeling}

PROTEUS-NODAL has a flowing fuel modeling capability which is essential feature for molten salt reactor analyses. In order to facilitate the flowing fuel module in PROTEUS-NODAL, a flow of molten salt or similar should be properly defined through the material assignment and driver input files along with a DLAYXS file which contains delayed neutron data. A process to setup the fuel flows can be categorized into flow path configuration and flow control.

\subsubsection{Flow Path Configuration}

A flow of molten salt fuel is specified through REGION_PROPERTY keyword in assignment file. Using the CHANNEL_ID property name, the moving fuel regions are linked and PROTEUSNODAL recognizes that the fuel flows through the blocks with the same channel ID from bottom to top direction. The two channel configurations shown in Figure 11 can be specified using the keywords given in Figure 12. In this example, the fuel in channel 1 will flow sequentially from A_01 to A_05 blocks and then return to the bottom of A_01 block. 

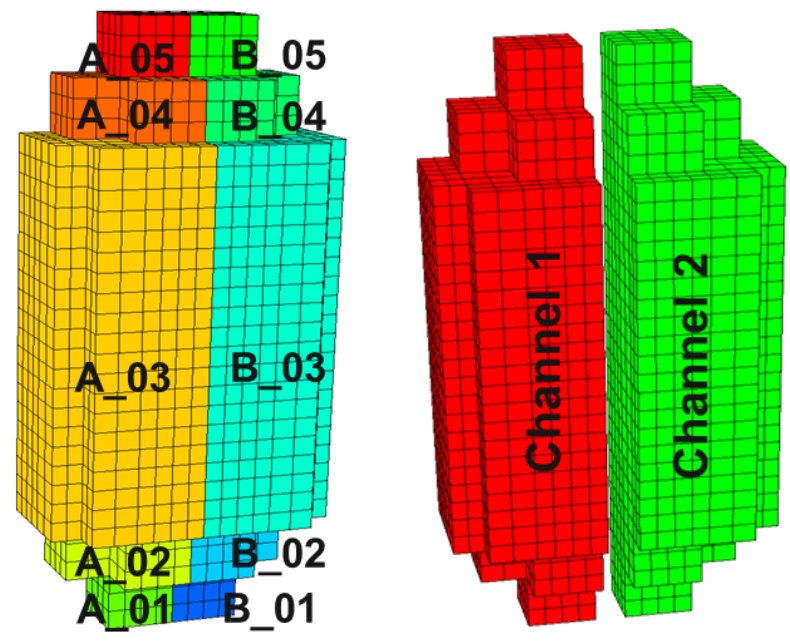

Figure 11. Illustration of Flow Channel Configurations

\begin{tabular}{|c|c|c|c|}
\hline Keyword & Block Name & Property Name & Value \\
\hline REGION_PROPERTY & A_01 & CHANNEL_ID & 1 \\
REGION_PROPERTY & A_02 & CHANNEL_ID & 1 \\
REGION_PROPERTY & A_03 & CHANNEL_ID & 1 \\
REGION_PROPERTY & A_04 & CHANNEL_ID & 1 \\
REGION_PROPERTY & A_05 & CHANNEL_ID & 1 \\
REGION_PROPERTY & B_01 & CHANNEL_ID & 2 \\
REGION_PROPERTY & B_02 & CHANNEL_ID & 2 \\
REGION_PROPERTY & B_03 & CHANNEL_ID & 2 \\
REGION_PROPERTY & B_04 & CHANNEL_ID & 2 \\
REGION_PROPERTY & B_05 & CHANNEL_ID & 2 \\
\hline
\end{tabular}

Figure 12. Configuring Flow Paths in Assignment File

\subsubsection{Fuel Flow Control}

In PROTEUS-NODAL, the fuel flow can be controlled using two parameters: velocity of individual blocks having moving fuel and delayed time from outlet to inlet of each channel (outside of each channel). The velocities of individual blocks are assigned using VELOCITY property name which is available in REGION_PROPERTY keyword. An example of velocity specification is given in Figure 13. Note that velocities should be carefully defined with $\mathrm{m} / \mathrm{s}$ unit such a way to preserver mass continuity of drifting precursors. The delayed time of each channel is specified using CHANNEL_INFO keyword in the driver input as illustrated in Figure 14. The first line in Figure 14 means the channel 1 named $\mathrm{CH}_{-} 001$ has a delayed time of $5.0 \mathrm{sec}$. 


\begin{tabular}{|c|c|c|c|}
\hline Keyword & Block Name & Property Name & Value \\
\hline REGION_PROPERTY & A_01 & VELOCITY & 2.751 \\
REGION_PROPERTY & A_02 & VELOCITY & 1.179 \\
REGION_PROPERTY & A_03 & VELOCITY & 0.323 \\
REGION_PROPERTY & A_04 & VELOCITY & 1.179 \\
REGION_PROPERTY & A_05 & VELOCITY & 2.751 \\
\hline
\end{tabular}

Figure 13. Assigning Velocities to Blocks in Assignment File

\begin{tabular}{|lllr|}
\hline CHANNEL_INFO & 1 & $\mathrm{CH}$ O01 & 5.0 \\
CHANNEL_INFO & 2 & $\mathrm{CH}$-002 & 5.0 \\
CHANNEL_INFO & 3 & $\mathrm{CH}$-003 & 5.0 \\
CHANNEL_INFO & 4 & $\mathrm{CH}$-004 & 5.0 \\
CHANNEL_INFO & 5 & $\mathrm{CH}$ - 005 & 50.0 \\
\hline
\end{tabular}

Figure 14. Assigning Delayed Times in Driver Input 


\section{Output Files}

Upon execution, as illustrated in Figure 15, PROTEUS-NODAL produces three basic types of outputs: (1) a main output text file, (2) a summary output file, and (3) a VTK file.

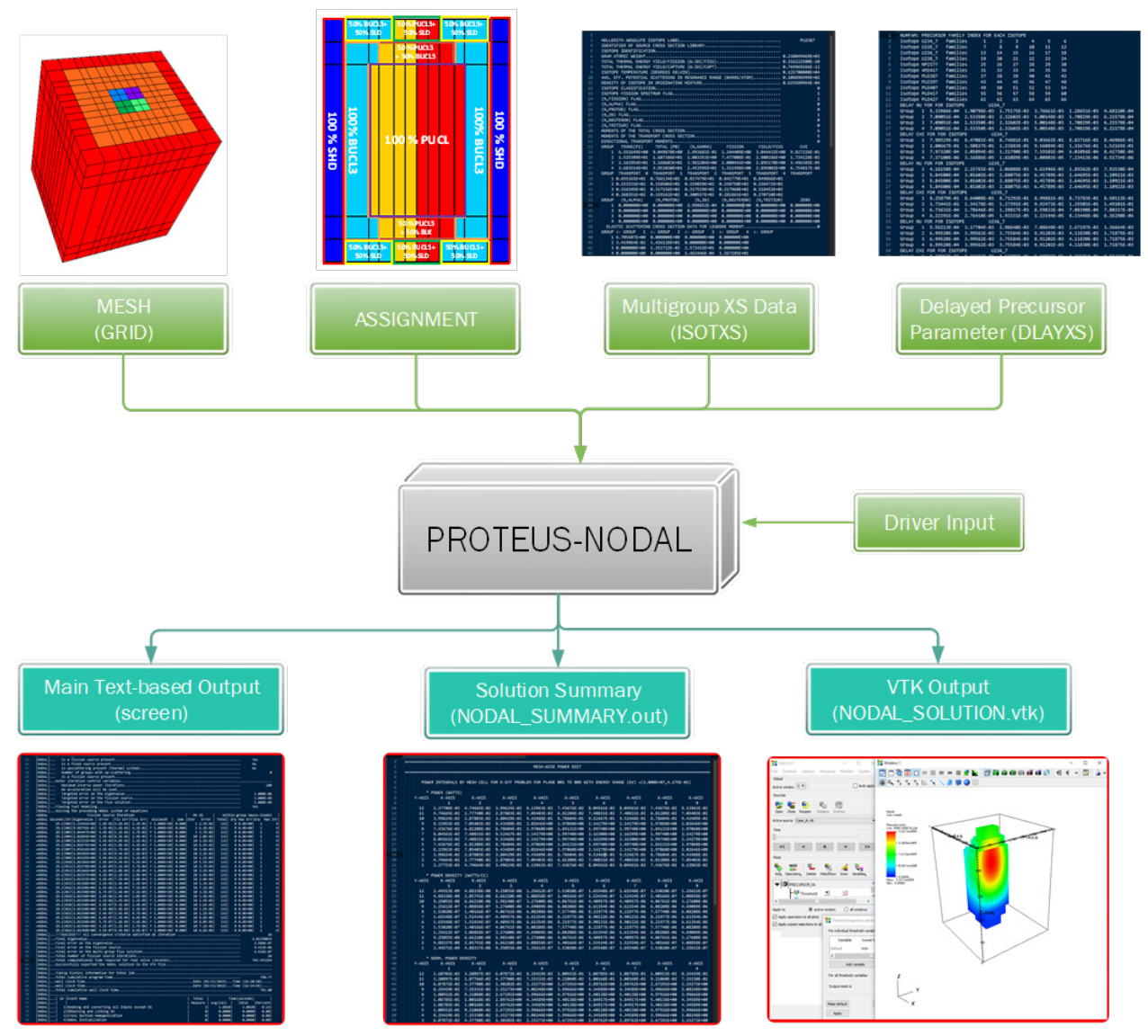

Figure 15. Schematic Illustration of Input and Output Files

\subsection{Main Output File}

The main text-based output is printed to a standard output or to a file if the "-output" option is used. The output contains confirmation that the input was imported successfully, parallel timing summaries, and eigenvalue iteration history results.

At the top of the file, the various input options are echoed and errors are produced if the input files were not successfully imported. This section is followed by the outer iteration history which reports the eigenvalue (and other quantities) as the calculation proceeds. At the end of the outer iteration history, the final eigenvalue is reported along with an error estimate. At the end of the output file, a timing history provides an overview of where time was spent in the calculation. 


\subsection{Summary Output File}

The summary of full solution in the entire domain is exported to an organized ASCII file for detailed analysis. The summary output file, named NODAL_SOLUTION.out, contains the following data: (1) region configuration and associated material mapping, (2) region-wise integrals for flux, power and fission source, (3) mesh-wise distributions for flux and power, and additionally (4) mesh-wise distributions for precursor if the flowing fuel option is turned on. These data are edited out with the user-friendly table format. Note that the total power is normalized to the user-specified value of THERMAL_POWER given in the main driver input.

\subsection{VTK File}

PROTEUS-NODAL exports the full 3D solutions in the VTK file format with the EXPORT_SOLUTION_VTK option on in the main driver input. The resulting VTK file, named NODAL_SOLUTION.vtk, is readable by VisIt or any visualization software which accepts a VTK format. This option can be invoked to visually examine or demonstrate the full 3D NODAL solutions. 


\section{Example Problems}

The test case selected as an example problem is a steady-state calculation for a 3D full core with flowing $\mathrm{PuCl}_{3}$ molten salt fuel. The following input files are required to solve this problem:

- Main driver input file

- Geometry \& mesh file

- Cross section file

- Material assignment file

Examining the driver input file in Figure 16, we see that the paths to the mesh, cross section data, and material assignment file are clearly defined by the SOURCEFILE_MESH, SOURCEFILE_XS, and SOURCEFILE_MATERIAL keywords. For this test case, SOURCEFILE_DELAY should be specified to calculate the delayed neutron contributions to the total neutron fluxes with respect to the speed of flowing fuel salt. In addition, the time for which the moving fuel spends from outlet to inlet of each channel is specified using CHANNEL_INFOR keyword. The mesh and full solution is exported to a VTK file named NODAL_SUMMARY.vtk if EXPORT_SOLUTION_VTK is set to YES.

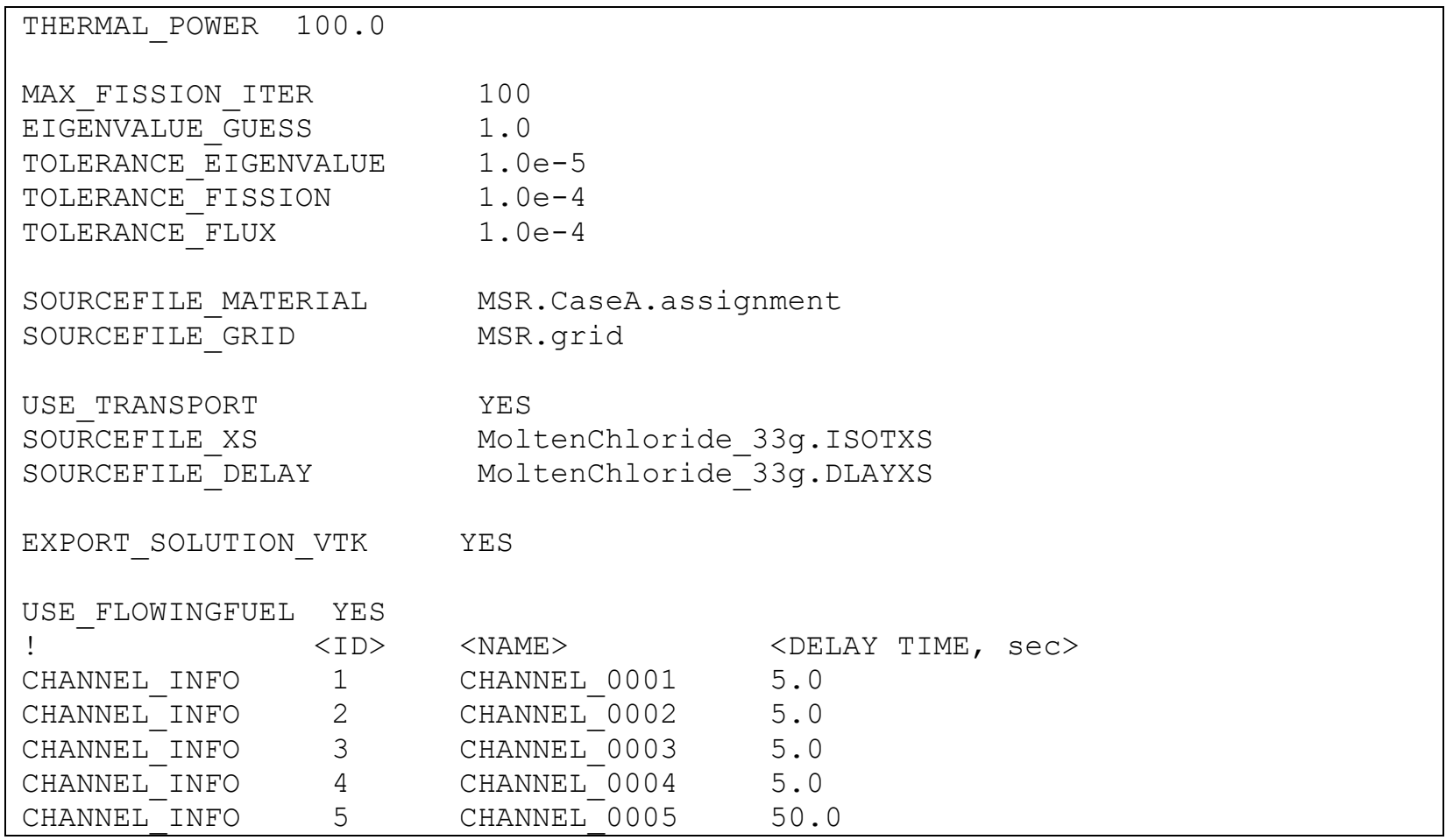

Figure 16. Driver Input File for Example Case 
The cross section file is generated using $M C^{2}-3$. The details of cross section generation are presented in Reference 13. In this test case, the isotopic cross sections for fuel, blanket, and shield regions are generated with homogeneous mixture.

The mesh input is generated for a 3D core in the GRID format, as shown in Figure 17. The input is directly read by PROTEUS-NODAL, which can also be verified by using the mesh generation toolkit. The detailed information on generating a GRID file is presented in Reference 3. The region names, such as FUEL_A_1, BLK__ 1, etc., specified in ASSEMBLY card are used in the material assignment file to link between region and material. Figure 18 is a snapshot of the VTK plot at the core center.

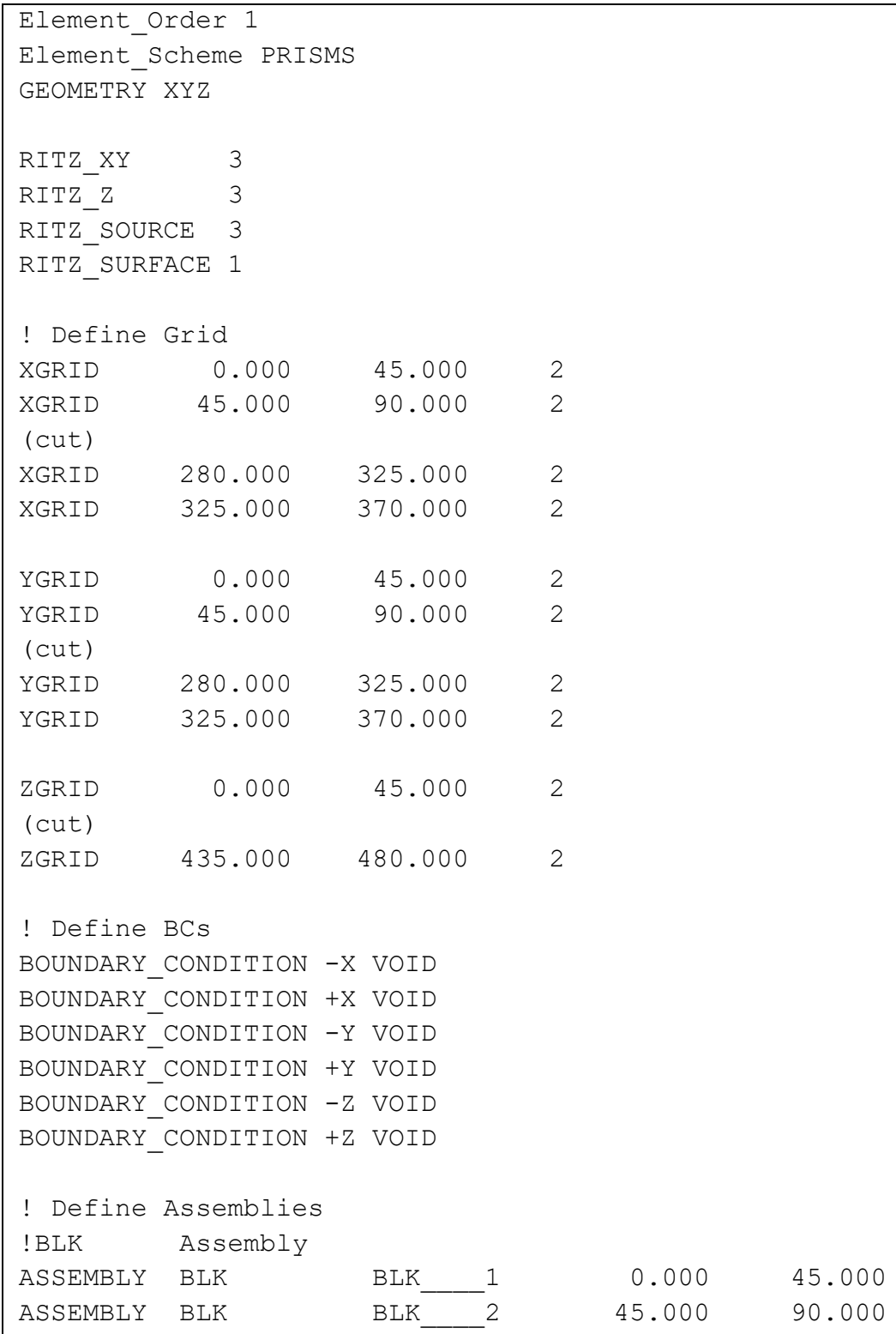


PROTEUS-NODAL User Manual

September 30, 2018

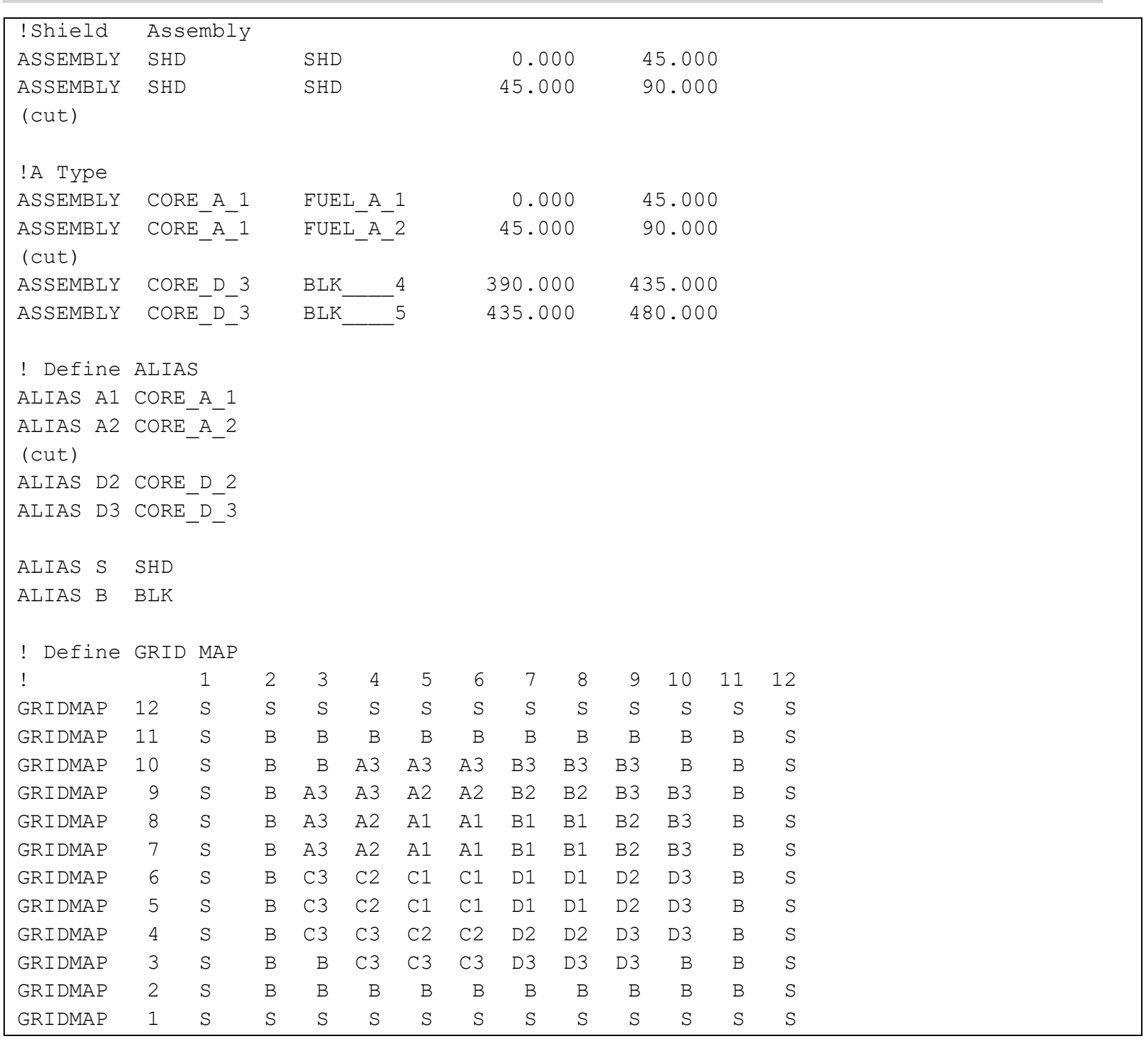

Figure 17. Mesh File for Example Case 

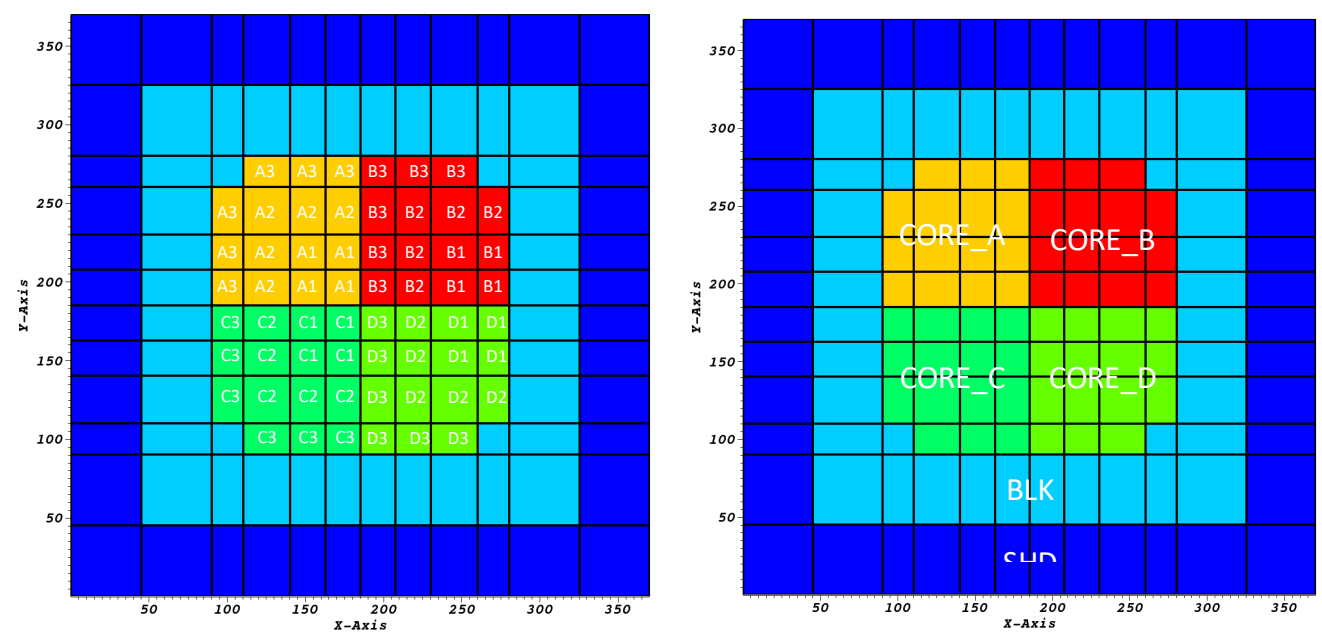

Figure 18. Region Map from the Mesh File at the Core Center

Part of the assignment file is shown in Figure 19. The MATERIAL_DEF card is used to define compositions with isotopes, which can be recursively used as shown in the example. PUCL3 and SHD are first defined and then those are used to define FUEL_1 using the MAETERIAL_DEF card. The REGION_PROPERTY card specified total atom number densities for the regions which are defined in the mesh file. The same card is used to determine CHANNEL_IDs which should be corresponding to the channel IDs defined in the main driver input. The velocities in $\mathrm{m} / \mathrm{s}$ within channels are defined using VARIABLE_DEF, which are used in the REGION_PROPERTY card to assign velocities to channels.

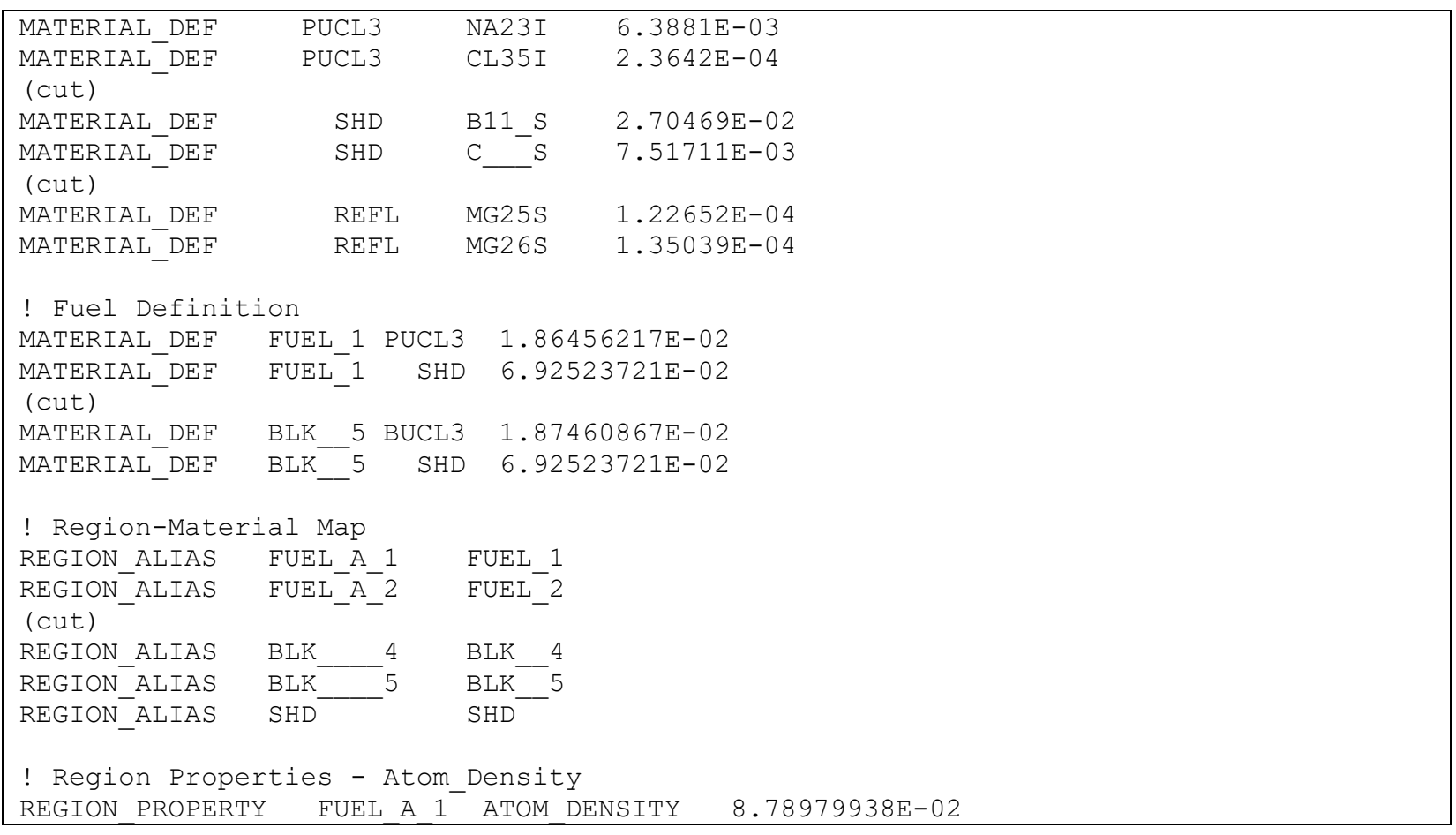




\begin{tabular}{|c|c|c|c|}
\hline $\begin{array}{l}\text { REGION_PROPERTY } \\
\text { (cut) }\end{array}$ & FUEL_A_2 & ATOM_DENSITY & $6.72562088 \mathrm{E}-02$ \\
\hline REGION_PROPERTY & SHD & ATOM_DENSITY & $1.38504744 \mathrm{E}-01$ \\
\hline ! Define Flow ch & Iannel & & \\
\hline REGION_PROPERTY & FUEL_A_1 & CHANNEL_ID & \\
\hline $\begin{array}{l}\text { REGION_PROPERTY } \\
\text { (cut) }\end{array}$ & FUEL_A_- 2 & CHANNEL_ID & \\
\hline REGION_PROPERTY & BLK___ 4 & CHANNEL_ID & \\
\hline REGION_PROPERTY & $\mathrm{BLK} \quad 5$ & CHANNEL_ID & \\
\hline ! Region Proper & cties - Veloc & Ey $(\mathrm{m} / \mathrm{s})$ & \\
\hline VARIABLE_DEF & FUEL_V_1 $=$ & 2.751 & \\
\hline $\begin{array}{l}\text { VARIABLE_DEF } \\
\text { (cut) }\end{array}$ & FUEL_V_- $2=$ & 1.179 & \\
\hline VARIABLE_DEF & BLK $V_{-} 4=$ & 0.0282 & \\
\hline VARIABLE_DEF & BLK_V_5 = & 0.0261 & \\
\hline REGION_PROPERTY & FUEL_A_1 & VELOCITY & $V_{-} 1$ \\
\hline $\begin{array}{l}\text { REGION_PROPERTY } \\
\text { (cut) }\end{array}$ & FUEL_A- 2 & VELOCITY & $\mathrm{V}^{-} 2$ \\
\hline REGION_PROPERTY & BLK & VELOCITY & V__ 4 \\
\hline REGION PROPERTY & $\mathrm{BLK}$ & VELOCITY & $\mathrm{V} 5$ \\
\hline
\end{tabular}

Figure 19. Material Assignment File for Example Case.

Once the four inputs (driver, cross section, mesh, and material assignment inputs) are prepared, the following command executes the code:

\$ nodal.x -input user.inp -output user.out

\$ nodal_sp3.x -input user.inp -output user.out

We have assumed that the executable and input files all reside in the working directory. After execution, the following files are produced:

- user.out

- NODAL_SUMMARY.out

- NODAL_SUMMARY.vtk

The first file, user.out, is the main text-based output file containing the eigenvalue and timing, as shown in Figure 20. The second file, NODAL_SUMMARY.out, is the formatted output file containing the full solution. The last file, NODAL_SUMMARY.vtk, is a VTK format file containing power, group flux, and precursor data for plotting using the visualization software, as illustrated in Figure 21.

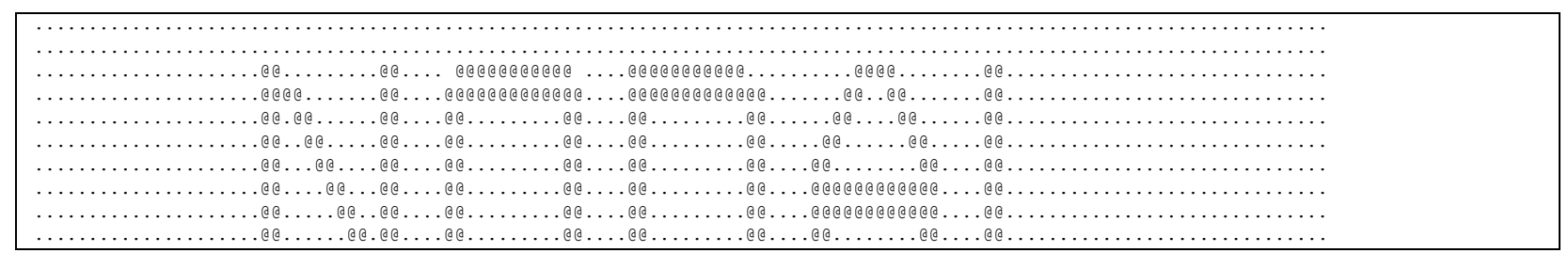




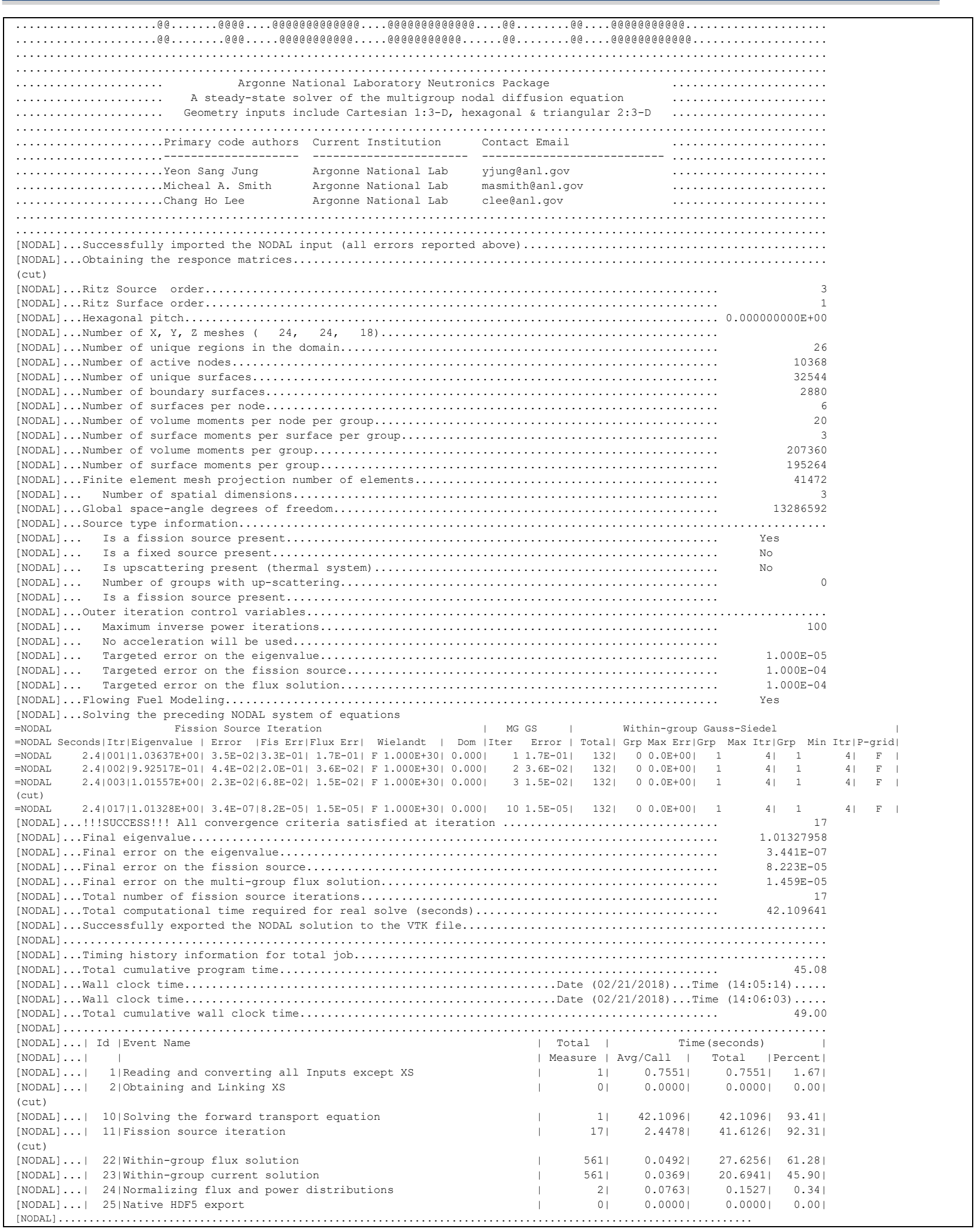

Figure 20. Main Output for the Test Case 

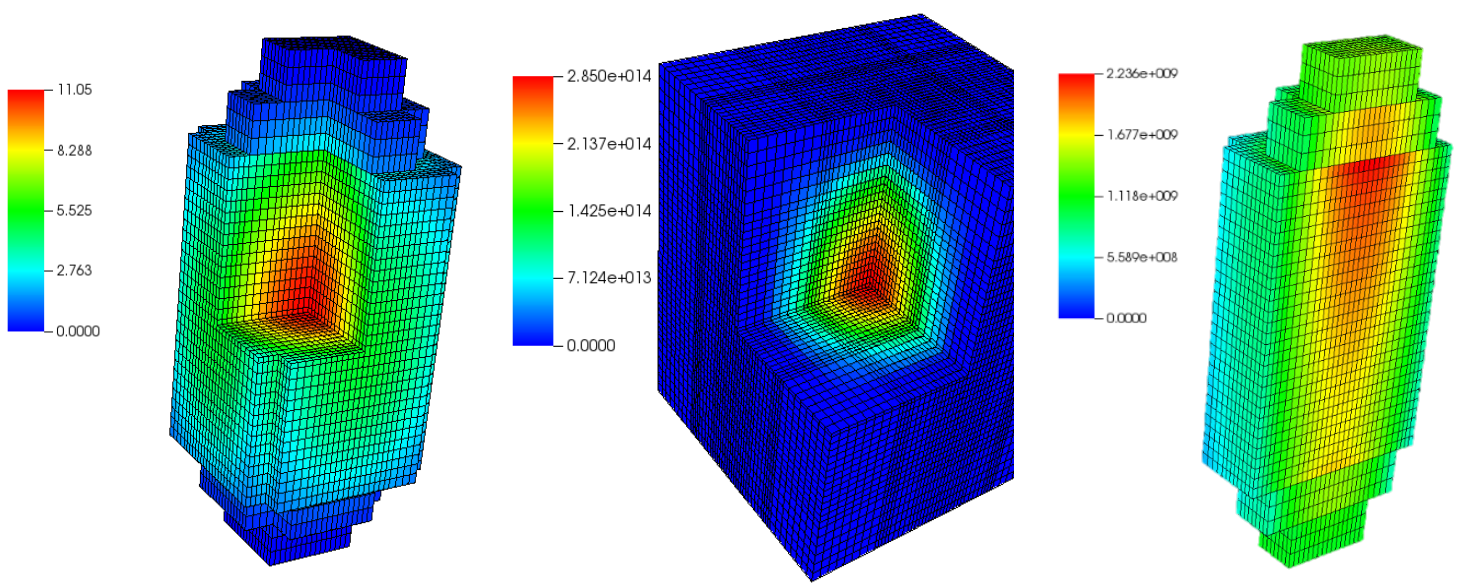

Figure 21. Power Density (left), Fast Neutron Flux (middle), and Precursor Family 1 (right) for the Test Case Plotted in VisIt 


\section{References}

1. G. PALMIOTTI, E.E. LEWIS, and C.B. CARRICO, "VARIANT: VARIational Anisotropic Nodal Transport for Multidimensional Cartesian and Hexagonal Geometry Calculation," ANL-95/40, Argonne National Laboratory, 1995.

2. M.A. SMITH et al., "DIF3D-VARIANT 11.0: A Decade of Updates," ANL/NE-14/1, Argonne National Laboratory, January 2014.

3. M.A. SMITH and E.R. SHEMON, "User Manual for the PROTEUS Mesh Tools," ANL/NE15/17 Rev. 2, Argonne National Laboratory, September, 2016.

4. VisIt Web Page, https://wci.llnl.gov/simulation/computer-codes/visit.

5. MPICH Web page, http://www.mpich.org.

6. METIS Web page, http://glaros.dtc.umn.edu/gkhome/metis/metis/overview.

7. The HDF Group. Hierarchical Data Format, version 5, 1997-2014. http://www.hdfgroup.org/HDF5.

8. E.R. SHEMON, M.A. SMITH, and C.H. LEE, "PROTEUS-SN Methodology Manual," ANL/NE-14/5, Argonne National Laboratory, June, 2014.

9. E.M. GELBARD, "Application of Spherical Harmonics Methods to Reactor Problems," WAPD-BT-20, Bettis, Atomic Power Laboratory, 1960.

10. J.Y. CHO, H.G. JOO, B.O. CHO and S. Q. ZEE, "Hexagonal CMFD Formulation Employing Triangle-based Polynomial Expansion Nodal Kernel," Proc. M\&C 2001, Salt Lake City, UT, USA, September 2001.

11. M. H. BAE, "Development of Triangle-based Polynomial Expansion Nodal $\mathrm{SP}_{3}$ Method for Hexagonal Core Transport Calculation," Seoul National University, 2010.

12. C.H. LEE et al, "FY17 Status Report on NEAMS Neutronics Activities," ANL/NE-17/28, Argonne National Laboratory, September, 2017.

13. C.H. LEE and W.S. YANG, "MC²-3: Multigroup Cross Section Generation Code for Fast Reactor Analysis," Nucl. Sci. Eng., 187, 268-290, June 2017.

14. G. MARLEAU, R. ROY, and A. HÉBERT, "DRAGON: A Collision Probability Transport Code for Cell and Supercell Calculations," Report IGE-157, Institut de génie nucléaire, École Polytechnique de Montréal, Montréal, Québec, 1994.

15. J. LEPPANEN, "Serpent - a Continuous-energy Monte Carlo Reactor Physics Burnup Calculation Code," VTT Technical Research Centre of Finland, June, 2015.

16. P.K. Romano et al., "OpenMC: A State-of-the-Art Monte Carlo Code for Research and Development," Ann. Nucl. Energy, 82, 90, 2015.

17. N.E. Staff, P.K. Romano, C.H. Lee, and T.K. Kim, "Verification of Mixed Stochastic/Deterministic Approach for Fast and Thermal Reactor Analysis," ICAPP 2017, Fukui and Kyoto, Japan, April 24-27, 2017. 


\section{Argonne}

Nuclear and Science Engineering Division

Argonne National Laboratory

9700 South Cass Avenue, Bldg. 208

Argonne, IL 60439-4842

www.anl.gov

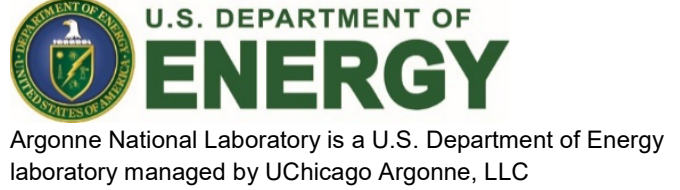

